\title{
MOSAICOS CON DECORACIÓN GEOMÉTRICA Y VEGETAL DE LA VILLA ROMANA DE EL RUEDO (ALMEDINILLA, CÓRDOBA)
}

\author{
Rafael HIDALGO PRIETO(*)
}

\section{Introducción}

El yacimiento de El Ruedo, objeto de nuestro estudio, fue excavado entre los meses de octubre de 1988 y julio de 1989. Dicha excavación fue efectuada por un equipo de investigadores adscrito al Área de Arqueología de la Universidad de Córdoba, dirigido por D. Vaquerizo, con la colaboración de F. Quesada, codirector durante la primera fase de la intervención de urgencia, y de licenciados y alumnos de las universidades de Sevilla, Autónoma y Complutense de Madrid.

Como resultado de estos trabajos, se ha podido recuperar una interesante villa romana y una de sus necrópolis inmediatas. Se trata de una villa de peristilo, cuyo origen podemos situar en la segunda mitad del s. I, alcanzando su ocupación al menos hasta finales del siglo V (1). La última fase constructiva, la mejor conservada, supone una importante obra de remodelación y embellecimiento de la casa, y a ella corresponde la mayoría de los mosaicos recuperados.

Junto al repertorio musivo, cabe citar la existencia de gran cantidad de paneles de estuco decorado conservados in situ. En la mayor parte de los casos, estos lienzos estucados alcanzan una altura aproximada de un metro, en ellos, la decoración más frecuente es la imitación marmórea, con una amplia variedad tipológica (2).

(*) Universidad de Córdoba.

(1) Sobre aspectos generales de El Ruedo y sus fases constructivas pueden consultarse los trabajos de D. Vaquerizo (1990a y b), J.R. Carrillo (1990) y S. Carmona (1990).

(2) Al igual que los mosaicos, la decoración pictórica llama la atención por la ausencia generaliza de motivos figurados. En el caso de la pintura contamos con un único ejemplo constituido por un personaje inscrito en un tondo, del que sólo se conservan las piernas (HIDALGO, 1990: 118). El estudio del conjunto pictórico presenta especial interés en función de la decoración musiva, ya que corresponde a la misma fase constructiva y porque es la combinación de ambos lo que constituye el repertorio decorativo de cada estancia. 
Finalmente, hacer referencia al conjunto escultórico recuperado en el yacimiento (VAQUERIZO, 1990c) con piezas cuya cronología abarca desde el siglo I de la era hasta principios del siglo IV, y entre las que destaca el Hypnos en bronce.

\section{Los mosaicos}

Se ha documentado un total de 13 mosaicos de los que cuatro están completos. Del resto, algunos se han recuperado casi en su totalidad, mientras que de otros sólo conservamos débiles vestigios. Los mosaicos completos corresponden a las estancias LIX, LXI, XXXVII y VIII; por su parte, los incompletos se sitúan en las estancias XVII, IX, XI, XIX, XXXn y XXXIII (fig.l).

El pavimento de las estancias LVII, LVIII y LX no es musivo como en las hasta ahora citadas, sino que está formado por una capa de cal y otra de opus signinum. Posiblemente estos son los restos de la cama de los mosaicos, totalmente perdidos (CARRILLO, 1990: 95-96).

En todos los mosaicos se representan exclusivamente motivos geométricos y vegetales. No se ha conservado resto alguno de decoración figurada ni indicio de que ésta existiese. Los motivos geométricos empleados son los habituales en la musivariaromana: peltas, nudos de Salomón, trenzas de dos y tres cabos, esvásticas, guiloches, filetes simples, dentados, etc. Por su parte, los motivos vegetales incluyen roleos, volutas, hojas de hiedra, flores de ocho pétalos, etc. En general predomina la decoración geométrica sobre la floral y vegetal, aunque en algunos casos -como en el mosaico 4- se invierte la relación.

\section{$N^{e}$ I. Mosaico con ruedas de peltas}

Se encuentra en la estancia LXI (fig. 1) y es uno de los mejor conservados de El Ruedo. Cubre un espacio rectangular y presenta un retranqueo en el ángulo noroeste con el fin de adaptarse a las escaleras de acceso a la sala inmediata. Las dimensiones totales de la estancia son $450 \mathrm{~cm}$. por $350 \mathrm{~cm}$., ocupando las escaleras una superficie de $150 \mathrm{~cm}$. por $130 \mathrm{~cm}$.

Esta estancia se concibe como lugar de distribución que da paso a los espacios LIX, LX y LXII. De ellos, el primero también presenta un pavimento musivo, cuyas teselas conectan perfectamente con las del que ahora nos ocupa.

En cuanto a la decoración representada, en este caso es totalmente geométrica (3), no apareciendo ningún motivo vegetal. El campo está cubierto por una composición de ruedas de peí tas alrededor de un nudo de Salomón. Los extremos de las peí tas contiguas

(3) Para la descripción de los motivos geométricos hemos empleado la terminología propuesta por C. Balmelle (BALMELLE y otros, 1985). 
se conectan mediante una voluta y los espacios intermedios entre las ruedas se completan con pequeñas flores cuatripétalas bícromas en aspa.

El campo está delimitado por una triple franja: la primera constituida por un filete triple, la segunda formada por un filete denticulado (dentículos de $3 \times 3$ teselas) y, finalmente, un último filete, en este caso doble. La composición queda algo desplazada ya que deja una franja libre junto al muro norte. Este espacio se completa con un nuevo elemento decorativo: una galería de arcadas compuestas por peltas continuas de cuyos extremos arrancan columnas, en las que esquemáticamente se ha representado el capitel y la basa (lám. II). En el apéndice se adosa un triángulo igual al utilizado para la representación de los capiteles. En total se han diseñado siete arcos. De ellos, el último sólo se ha realizado parcialmente debido a la falta de espacio.

El repertorio decorativo de esta estancia se completa con un último elemento, situado en la entrada principal, totalmente ajeno al resto de la composición. Se trata de un cuadrado formado por un filete triple en cuyo interior se inscribe, tangente, un cuadrado bícromo de lados curvos.

La totalidad de los mosaicos de El Ruedo son polícromos, utilizándose para ello, como es habitual, materias naturales que proporcionan una cromía no muy intensa (4). El caso concreto de este mosaico destaca por la utilización predominante del negro. La arquería de peltas, las ruedas de peltas y los filetes que las delimitan se han representado en negro, sólo las peltas de la arquería mantienen un espacio en blanco en su interior. El motivo de la entrada incluye la bicromía únicamente en el cuadrado tangente interior, en negro y rojo. Por su parte, los nudos de Salomón y las pequeñas flores cuatripétalas se representan en policromía. Los colores utilizados son rojo, marrón, amarillo, salmón y gris. No se emplean de forma regular sino que van cambiando de un nudo a otro y de una flor a otra.

Las dimensiones de las ruedas de peltas son de $45 \mathrm{~cm}$. (distancia máxima entre arcos de peltas opuestas), mientras que los nudos inscritos tienen un tamaño de $27 \mathrm{~cm}$. Por su parte, la arquería alcanza una altura total de $43 \mathrm{~cm}$. desde la base hasta la clave; la al tura de las columnas es de $25 \mathrm{~cm}$. y el espacio del intercolumnio es de $32 \mathrm{~cm}$. Finalmente, el cuadrado de la entrada mide $58 \mathrm{~cm}$. de lado (5).

La rueda de peltas constituye un esquema ornamental muy común en los mosaicos romanos (6). Estas pueden representarse con cuadrados inscritos (BALMELLE y otros, 1985: n² 223) (7), esvásticas (BECATTI, 1961: 123, lám. XLVII) o florecillas en aspa (BALMELLE y otros, 1985: $\mathrm{n}^{2} 223$ ).

(4) El estudio y análisis de los materiales empleados para fabricar las teselas se encuentra actualmente en curso, por ello, la presentación y exposición de sus resultados queda relegada a posteriores trabajos.

(5) Las medidas aportadas son siempre distancias medias ya que estas no suelen ser exactas y regulares.

(6) La pelta como elemento decorativo aparece aplicada al mosaico en el s. I a.C. como resultado de la creatividad de los musivaríos que diseñaron los pavimentos pompeyanos (OVADIAH, 1980: 145).

(7) Para Blanco $(1978,16)$ este modelo es más antiguo, siendo reemplazado por el nudo de Salomón central a mediados del s. II. 
La variedad que aquí encontramos, con nudo central, aparece ya definitivamente formada en época de Adriano (CORPUS VIII, 42-44) (8). Puede presentarse como elemento aislado, normalmente circunscrita por un pequeño marco cuadrado, formando una orla en torno al pavimento o constituyendo el motivo principal del campo, diseñándose en esquema continuo.

Como elemento aislado la podemos encontrar en Cabanas de la Sagra en Toledo (CORPUS V, $n^{9}$ 27,40 ss., láms. 24-25); en Mérida en un pavimento del s. IV (ALVAREZ, 1990: fig. 7); en la villa de los Cipreses en Jumilla (CORPUS IV, nº 85,78, lám. 37), en un pavimento en el que las peltas, inscritas en un círculo, terminan en volutas al igual que en El Ruedo, y cuya cronología se establece en tomo a la mitad del s. IV. En Britania esta decoración es muy habitual y se documenta ya en el s. II en Boxmoor y Silchester (SMITH, 1975: lám. CX 1 y 2); y en Gloucestershire (JOHNSON, 1982:39, lám. 27) y Lincolnshire (JOHNSON, 1982:49, lám. 38) a comienzos y finales del s. IV respectivamente, siendo también muy frecuente durante el s. III, En Ostia lo encontramos en la Ínsula de la musa en torno al 130 d.C. También aparece en el norte de África, de donde a modo de ejemplo podemos citar un caso procedente de Tipasa (DUVAL 1975: lám. XXXI 2) de la segunda mitad del s. IV o primera mitad del V.

En lo que respecta a las ruedas de peltas en orlas o bandas, en España citaremos los

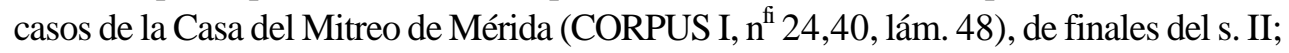
el de la calle Sagasta de la misma ciudad (CORPUS I, $n^{\text {s }}$ 10,32-33, lám. 21), fechable en el s. IV; el de la villa de Bobadilla (RODRÍGUEZ OLIVA, 1988:160-166), de la primera mitad del s. III; el procedente de la villa burgalesa de Baños de Valdearados (ARGENTE, 1979:65 y ss., fig. 20), de la primera mitad del s. V, y el de la villa del Camino Viejo de las Sepulturas en Balazote (CORPUS VIII, $n^{9} 32,42-44$, fig. 9), en una curiosa orla en la que las ruedas de peltas se alternan con sandalias y un recipiente, fechado en el s. IV. Ruedas de peltas terminadas en volutas, aunque en este caso con un cuadrado en el interior en lugar del habitual nudo de Salomón, las encontramos en un mosaico de Mérida de fines del s. IV o inicios del siguiente (CORPUS I, $n^{9} 13,33$, lám. 24a). En Lyon se conserva un mosaico del s. III (RECUEIL II-1,112, lám. LXXIX), con las ruedas de peltas en doble línea. En Britania aparece en un mosaico de Roxby (JOHNSON, 1982: 48, lám. 37), rodeando todo un mosaico cuadrado, fechable en el tercer cuarto del s. IV. Este tipo de

(8) Debido a la amplia difusión tanto del Corpus de mosaicos romanos de España, como del Recueil General des mosatques de la Gaule hemos preferido referimos a ellos como Corpus y Recueil, en lugar de citar su autor o autores. La correspondencia por autores y fechas de los fascículos citados seria:

Corpus I: Blanco, 1978a

Corpus II: Blanco, 1978 b

Corpus HI: Blázquez, 1981

Corpus IV: Blázquez, 1982a

Corpus V: Blázquez, 1982b

Corpus VI: Blázquez y Ortego, 1983

Corpus VIII: Blázquez y otros, 1989a

Corpus IX: Blázquez y otros, 1989b
Recueil 1-1: Stem, 1957

Recueil 1-2: Stem, 1960

Recueil 1-3: Stem, 1963

Recueil II-1: Stern, 1967

Recueil II-2: Stem y Blanchard, 1975

Recueil II-3: Darmon, 1977

Recueil U1-2: Lancha, 1981

Recueil IV-1: Balmelle, 1980 
orlas se encuentra además en la villa de las termas imperiales de Tréveris (HELLENKEMPER, 1975:335-336, fig. 1), fechado a mediados del s. III y formando también una orla continua.

Un último modelo, al que pertenece el procedente de El Ruedo, es aquél en el que todo el campo o una parte considerable de éste aparece cubierto de numerosas ruedas de peltas. En la Península disponemos del mosaico de la loba y los gemelos de Villacarríllo (CORPUS III, $\mathrm{n}^{\mathrm{fl}}$ 52,72, lám. 60), actualmente perdido, en el que el esquema de ruedas de peltas sirve de complemento a un canevás típico de esquema a compás, cuya cronología se establece en el s. II. También en Mérida contamos con un ejemplo de este tipo, en la Casa del Mitreo (CORPUS I, n 34,43, lám. 67a), del s. III. Otro mosaico con ruedas de peltas en el campo es el de la villa del Cortijo Auta de Riogordo (ARCOS ALVAREZ, 1988: lám. 9-10). En Pisóes (VARGAS, 1983-1985:123, fig. 6) se repite en una composición similar a la de Villacarrillo fechada en la primera mitad del s. IV.

En Ostia aparece con cierta frecuencia: en la ínsula de Dionisos (BECATTI, 1961: 196-197, lám. XLVIIl), en un pavimento de finales del s. II; en la domus de la gorgona (BECATTI, 1961:25, lám. XLVIII), en otro de finales del s. III o primera mitad del IV; en otra casa ostiense (BECATTI, 1961:183, lám. XLVIII) lo encontramos con peltas con interior en blanco, deis. IV d.C, y en la domus de los dioscuros (BECATTI, 1961:123, lám. XL VIl) sustituyendo el nudo central por una esvástica, en la segunda mitad del s. IV. En la Galia lo podemos encontrar en Medernach (RECUEIL1-2, nº 184,42, lám. XX) de la segunda mitad del s. II o principios del s. III, y en otro de la segunda mitad del s. II o inicios del s. m.

En lo que a las arquerías respecta, son un motivo muy utilizado para confeccionar bandas periféricas y, sobre todo, orlas que rodean y circunscriben el campo decorativo. Este tema, de origen itálico, aparece ya en el s. I a.G, en la vía Ardeatina fechado en época silana(NOGARA, 1910:8, lám. XVI). Existe una amplia variedad estilística de esta decoración (9). En algunos mosaicos, como en el procedente de Fishbourne (JOHNSON, 1982:14, lám. 4) fechado en 75-80 d.G, aparece como elemento secundario de una orla con murallas, constituyendo las portadas de las mismas. En otros, se representa de forma simplista y geométrica, como en los de La Quintanilla, Lorca (CORPUS IV, $n^{9} 53,61$, fig. 20), y Bavay (RECUEIL 1-1, no 113,76, lám. XL), de los siglos IV y II d.C. respectivamente, en ambos con los arcos intercalados con tímpanos. En otro mosaico, en este caso de inicios del s. III, procedente del Mitreo de las Siete Puertas de Ostia (BECATTI, 1961: n 378,198-199, lám. XVII) se representa un arco grande central sobre dos pilastras con capiteles, flanqueado por tres arcos más pequeños a cada lado (10).

(9) Sobre la tipología del motivo véase el estudio de Balmelle (1985: no 96-97).

(10) En este caso el artesano adaptó un motivo del repertorio de cartones tradicionales, dándole un significado simbólico: el mosaico es colocado a la entrada de la estancia para simbolizar las siete puertas que ha de atravesar el alma del fiel de la religión mitraica. Cada una de estas puertas estaba tutelada por una divinidad planetaria, representadas también en la estancia. 
El modelo más habitual es el constituido por una arquería continua realizada mediante un filete monocromo, con columnas diseñadas del mismo modo en las que también se representa capitel y basa. A este modelo corresponden los mosaicos de Ansa (RECUEIL II-2, n 175,30 ss., lám. V-IX), con proas de naves en el interior de los arcos y fechable en época de los severos; Rielves, Toledo (CORPUS V, 61 y ss., fig. 40), con florecillas en aspa en el interior de los arcos, del s. IV; El Hinojal (CORPUS I, nº 63,51-52, fig. 4), en Mérida, con crucecillas y esvásticas alternando sin regularidad en el interior de los arcos, también del s. IV y Los Cipreses (Jumilla, Murcia) (CORPUS IV, $n^{\text {oi }} 84$, 72, fig. 24), repitiendo la cronología del s. IV. Muy similar a los anteriores es un mosaico de Marios (CORPUS III, $\mathrm{n}^{\circ}$ 42,62, lám. 51) fechado en el s. III, en el que al esquema ya descrito se le añaden tímpanos sobre pares de arcos. En el baptisterio de Grado (MIRABELLA, 1975: 203, lám. LXIX-2) lo encontramos compartiendo con el de Almedinillalapeculiaridad de presentar los arcos representados por peltas, diferenciado sólo porque sitúa una columna también en el apéndice.

La utilización de orlas y bandas con arquerías corridas perdura hata época tardía como demuestran un mosaico de Taran (RECUEIL IV-1,nº 108,112 ss., lám. XLIX) de finales del s. TV o s. V, el mosaico de Gafra (DUNBABIN, 1978:92, lám. XXX), posiblemente del s. VI, o el de la iglesia de Saint-Irénéé de Lyon (RECUEIL II-1, nº 6*. 124 y ss., lám. XCIV), con el tema ya muy evolucionado y fechado en el s. XII.

\section{$N^{o}$ 2. Mosaico con estrella de ocho losanges}

Está formado por un cuadrado delimitado por una trenza continua de tres cabos que constituye el marco. Gran parte del campo aparece ocupado por un esquema de grandes dimensiones representando una estrella de ocho losanges, situadas dos a dos (lám. IV). Las losanges aparecen delimitadas por un filete en negro y en el interior de cada una de ellas se inscriben otras cuatro superpuestas y en distintos colores.

La estrella circunscribe cuatro cuadrados en los vértices y otros tantos triángulos en los laterales. Tanto los cuadrados como los triángulos van decorados al interior. En los primeros se incluye un marco con una banda de dientes de sierra dentellados en oposición de colores, y en su interior, separado por un filete simple, un nudo de Salomón tangente. En los segundos, el marco está formado por dos filetes, uno simple y otro con dentículos de cuatro teselas; en ellos se inscribe una pelta bícroma con dos medias crucecitas en el interior.

El esquema de esta habitación, la estancia LIX, destaca por la utilización de trazos rectos en todos los diseños. La curva se usa sólo en el caso de las peltas, que se aplican como elemento de relleno.

Aquí también se incluye un cuadrado decorado coincidiendo con la entrada de la estancia. En este caso dentro del cuadrado aparece otro de menores dimensiones -ambos 
constituidos por un filete simple-, en el que se representa una línea de pequeños cuadrados tangentes sobre la punta. En los vértices del cuadrado mayor, estrellas de filetes triples dentellados en oposición de colores.

El color negro se ha empleado básicamente para los elementos de separación y para los secundarios. El resto de la composición presenta una variada policromía a base de marrón, ocre, amarillo, verde, gris y rosa.

La longitud total del gran cuadrado decorado es de $330 \mathrm{~cm}$. de lado. Por su parte, las losanges del esquema central presentan $145 \mathrm{~cm}$. de diagonal mayor y $45-50 \mathrm{~cm}$. de diagonal menor. Los cuadrados de los ángulos miden $65 \mathrm{~cm}$. de lado el exterior, y $35 \mathrm{~cm}$. el interior. El nudo de Salomón tangente alcanza los $30 \mathrm{~cm}$. de altura. En lo que respecta a los triángulos laterales, sus lados menores miden $68 \mathrm{~cm}$. cada uno, y la pelta de su interior presenta una altura de $23 \mathrm{~cm}$. Finalmente, el cuadrado de la entrada, sólo en blanco y negro, mide $60 \mathrm{~cm}$. de lado.

La estrella de ocho losanges (BALMELLE y otros, 1985: $\mathrm{n}^{8}$ 173-178) constituye un esquema decorativo muy antiguo, documentándose en Pompeya en el s. I a.C.

En cuanto a su origen, posiblemente se trata de la adaptación de una decoración propia del opus sectile al tessellatum. En los pavimentos más antiguos se representan las losanges en negro sobre fondo blanco, añadiendo polígonos, generalmente cuadrados, para completar el esquema. El motivo es empleado frecuentemente entre los siglos I y II con ciertas variaciones formales por parte de los artesanos.

La aplicación del diseño a los pavimentos musivos se materializa de distintas formas:

En primer lugar, puede aparecer formando motivos aislados, de mayor o menor tamaño, normalmente inscritos en cuadrados o polígonos, y formando parte de composiciones geométricas muy diversas.

Puede aparecer también como motivo continuo: el campo se rellena con toda una serie de estrellas conectando unas con otras mediante los extremos de las losanges. Los espacios intermedios se decoran con cuadrados rectos y apoyados sobre el vértice.

Un último modelo es aquel en el que se representa una única estrella de gran tamaño, en torno a la cual gira el resto de la decoración del pavimento. A este tipo correspondería el mosaico que nos ocupa.

En lo que a su difusión se refiere, en la Galia se conservan abundantes paralelos, siendo uno de los elementos más frecuentes en el repertorio rodanés. Como elemento secundario lo encontramos en Lyon (RECUEIL II-1, nº13,29-30, lám. XII), fechado entre los siglos II y III, en Autun (RECUEIL II-2, nº 229,270 ss., láms. XXXII-XXXIV) de la primera mitad del s. III, en Champuert (RECUEIL II-2, nº 326,122-123, láms. LXVI-LXVIII) con esquema ortogonal pero no continuo y fechado en la primera mitad del s. III, en la villa de Biches (RECUEIL II-2, nº 335, 127 ss., láms. LXII-LXIV) de época severiana y en Ouzouer-sur-Trézée (RECUEIL II-3, nº 467,93 ss., láms. LXVIII-LXXIII), de igual cronología que el anterior. 
El motivo repetido formando un esquema continuo lo encontramos en Orange (RECUEILIII-1, no 47,62 ss., láms. XIV y XV), en un pavimento de finales del s. I, en otro de Saint-Bertrand-de-Comminges (RECUEIL IV-1, nº 33,50 ss., láms. VI-VIII), de finales del s. I o primera mitad del s. II, en Reims (RECUEIL 1-1, no 42, 36-37, lám. XV) fechado entre los siglos I y II, en Saint-Paul-Trois-Cháteaux (RECUEIL III-1, n¹11,105 ss., láms. XL-XLI) datado entre 130-150 d.C, al igual que otro pavimento de Cavaillon (RECUEIL III-1, 77-78, lám. XXIII), en Feurs (RECUEIL II-2, nº 161,23-24, lám. I) de la primera mitad o mediados del s. II, en Nizy-le-Comte (RECUEIL 1-1, n9 49, 39-40, láms. XVI-XVIII) procedente de una villa y fechado en el s. II, en Paisy (RECUEIL II-3, $\mathrm{n}^{2}$ 509, 143 ss., láms. CVII-CXII) en torno a la primera mitad del s. III, y en Sens (RECUEIL II-3, no 425, 63 ss., láms. XLI-XLV), posiblemente de primeros del s. III. Finalmente, de Souzy-la-Briche (RECUEIL II-3, n 483, 115 ss., láms. LXXXIVLXXXVII) procede un último mosaico, con una cronología del s. IV o algo posterior.

La aparición de una única estrella como eje de la composición es bastante más escasa, encontrándose en Membrey (RECUEIL 1-3, no 366 E, 94-95, láms. LII-LVII) en un pavimento datado en torno al s. II, y en otro de Saint-Paul-Trois-Cháteaux (RECUEIL III1, no 107, lám. XXXIV), de finales del s. IV o inicios del s. V. Estos dos casos son los más similares a la composición de El Ruedo, especialmente el segundo, y principalmente en lo que a la policromía se refiere.

En Ostia se documenta también el tema de la estrella de ocho losanges como esquema continuo. Aquí se representa siempre el campo en blanco decorado con estrellas lineales en negro. En la domus fulminato (BECATTI, 1961: no 197, 106, lám. XXVII) lo encontramos en un pavimento datado en la segunda mitad del s. I; en la ínsula de la musa (BECATTI, 1961: nº 261,131, lám. XXIII) aparece fechado en tomo al 130 d.C; en la domus de Apuleio (BECATTI, 1961: nº 152, 89, lám. XXV) de mediados del s. II; en la ínsula de Dionisos (BECATTI, 1961: nº 374, 196, lám. XXVIII) de fines del s. II y, finalmente, en otro pavimento de la domus fulminato (BECATTI, 1961: $\mathrm{n}^{\circ}$ 205,108-109, lám. XXVII), en este caso fechado en la primera mitad del s. III.

En Britania aparece también como esquema ortogonal en Fihsbourne (SMITH, 1975: lám. CVII) fechado entre 75-80 d.C; en Colchester (SMITH, 1975: lám. CIX), anterior a Antonino; en Verulamium (SMITH, 1975: lám. CIX), datado a mediados del s. II, y en Lincolnshire (JOHNSON, 1982:49), en un ejemplo más tardío -tercer cuarto del s. IV- en el que aparece como esquema continuo y también como elemento complementario.

Finalmente, otros mosaicos con estrellas de ocho losanges, de nuevo en esquema continuo, los podemos encontrar en la misma Córdoba, en una reciente excavación, aún inédita, en la calle Ramírez de las Casas-Deza; en Alcolea del Río (CORPUS IV, nº 9,24, lám. 6) de la segunda mitad del s. II; en Mérida en esquema continuo en un mosaico fechado en el s. IV (ALVAREZ, 1990: fig. 7), o en Utica (ALEXANDER-ENNAIFER, 1974: $n^{2} 208,62$, lám. XXXVII) en un columbario fechado a inicios del s. II. 
El motivo de estrellas de ocho losanges no es válido como criterio de datación debido a que, como se observa en los ejemplos citados más arriba, se usa de forma continuada durante un amplio espacio de tiempo (11).

\section{$N^{o} 3$. Mosaico con composición en nido de abeja}

El esquema de esta estancia, la VIII en el plano general, gira en tomo a un círculo decorado que centraliza la composición. El círculo, separado de los demás elementos por un filete simple, está decorado por una línea de postas con enrollado múltiple en negro sobre fondo blanco (lám. V). En el interior, se inscribe un cuadrado decorado con filetes dentellados de seis teselas en arco iris. El motivo central aparece rodeado por una serie de cuadrados que trazan un octógono en torno suyo (B ALMELLE y otros 1985: $\mathrm{n}^{\circ}$ 205). En el espacio intermedio entre los cuadrados se forman triángulos que, al igual que los cuadrados, se decoran interiormente. En cuanto a los cuadrados, todos constan de un marco y un espacio central decorados con varios esquemas:

- El marco formado por una trenza doble polícroma y al interior un cuadrado dentellado.

- En el marco, una línea continua de dientes de sierra dentellados en oposición de colores. Al interior, par de peltas afrontadas y entre ambas, a los lados, dos cruces de cinco teselas.

- El último caso es muy similar al anterior. Mientras que el esquema interior continúa siendo el mismo, en el marco se sustituye la línea de dientes de sierra dentellados por una línea de espinas rectilíneas cortas en oposición de colores.

Con el primer modelo se decoran cuatro de los cuadrados, que se disponen enfrentados dos a dos y alternando con los otros cuatro. Estos últimos se decoran dos a dos con los dos modelos restantes y también se disponen enfrentados.

Los triángulos comprendidos entre los cuadrados se decoran alternativamente con hojas de hiedra con volutas y con triángulos inscritos bícromos.

El esquema del pavimento se completa con los motivos de los vértices. Aquí se ha trazado un cuarto de círculo compuesto por un marco múltiple: en primer lugar un filete simple en negro, seguidamente una línea quebrada en filete simple formando triángulos polícromos y, finalmente, una línea de dientes de sierra -de triángulos equiláteros- en oposición de colores. Al interior de este marco y coincidiendo exactamente con los vértices del mosaico, se incluye un cuadrado constituido por un filete simple negro en cuyo interior se inscribe, tangente, un cuadrado bícromo de lados curvos. Finalmente, en los ángulos del primer cuadrado, pétalos bícromos.

(11) Al respecto se puede consultar la obra de Salies (1974), con ejemplos desde el inicio del imperio hasta época tardía. 
Al canevás central que acabamos de exponer habría que añadir un cuadrado exento, situado en el umbral de la única puerta que comunica con esta estancia. Dicho cuadrado presenta en su interior un damero en blanco y negro con casillas de cuatro teselas (lám. VI).

La decoración del mosaico se completa con una policromía muy variada, culminando con elementos tan coloristas como el esquema de "arco iris" central. Los colores empleados son marrón, rojo, ocre, amarillo y gris azulado. En cuanto al color negro, sigue formando parte primordial del conjunto constituyendo todos los trazos del diseño.

El mosaico ocupa un espacio cuadrangular de $325 \mathrm{~cm}$. de lado. Por su parte, los cuadrados que constituyen el esquema de "nido de abeja" miden 70-75 cm. de lado, coincidiendo con el radio de los cuartos de círculo de los vértices. Los pequeños cuadrados que se inscriben en ellos alcanzan los $25 \mathrm{~cm}$. de lado. Finalmente, el esquema de damero de la entrada no llega a alcanzar los $60 \mathrm{~cm}$. de lado.

El canevás radial central es común en la musivaria romana a partir del s. I. Aparece habitualmente en composiciones continuas, siendo poco usual como esquema único (CORPUS III, 41). En el s. I lo encontramos en diversos mosaicos de Aquilea (BLAKE, 1930:113, lám. 39.4), Pompeya (BLAKE, 1930: fig. 2e) y Turín (BLAKE, 1930: 106, lám. 40.3). Por otra parte, de finales del s. V o incluso a principios del s. VI aún se conservan varios ejemplos en Antioquía (LEVI, 1947:323 ss., lám. CXI; 351 ss., CXXXV).

En Hispania lo encontramos en diversos pavimentos. En la misma Córdoba se conserva el thyasos báquico de Alcolea (CORPUS III, nº 21, 40, lám. 25-30) fechado entre 160-170, con representaciones figuradas tanto en el octógono central como en los rectángulos radiales. En otro mosaico no muy distante, el nacimiento de Venus de Cártama (CORPUS III, nº 61,85-88, láms. 70-71), aparece de nuevo con representación figurada en el centro y con una cronología similar al anterior, s. II, preferiblemente a finales. A la villa del Camino Viejo de las Sepulturas (CORPUS VII, $n^{\circ} 34,45-46$, fig. 11) pertenece un tercer pavimento, mucho más tardío, cuya cronología se establece en el s. IV. La misma datación ofrece otro pavimento, en este caso de Comunión (CORPUS V, $\mathrm{n}^{\mathrm{a}} 3$, 16, fig. 4, lám. 41), en el que el esquema en cuestión se completa exclusivamente con motivos geométricos. Finalmente, y ya en la primera mitad del s. V, encontramos un pavimento de Baños de Valdearados (ARGENTE, 1979:65 ss., fig. 20, láms. Xn-XVI) en el que el esquema aparece como elemento continuo. Como señala Blázquez (CORPUS HJ, 43), en parte de la Bética este esquema presenta la peculiaridad de realizarse a base de rectángulos radiales en lugar de mediante cuadrados. En nuestro caso esta tendencia no se ratifica, aplicándose cuadrados como es habitual en otras zonas.

El motivo de damero es muy común en los mosaicos romanos. Según Plinio (NH, XXXVI, 185) el primer pavimento de este tipo fue el que tras la tercera guerra púnica se realizó en el templo de Júpiter Capitolino. No se trata de una decoración inventada por los mosaístas sino que estos la copiaron, posiblemente de la cerámica pintada (OVADIAH, 1980:130). En la Península se conserva un modelo de gran antigüedad con esta decora- 
ción: el pavimento de cantos de Cástulo (FERNANDEZ GALIANO, 1984: fig. 2), de finales del s. VII a.C, por otra parte el mosaico más antiguo del Mediterráneo occidental. Como muestra de su amplia difusión y cronología podemos citar su presencia en uno de los pavimentos de la villa de Cabra (CORPUS III, $n^{\circ} 31$, 49-50, fig. 17), fechado a comienzos del s. III, en el que aparece formando parte del campo, en otro de Utica (ALEXANDER-ENNAIFER, 1974:6, lám. UI) también del s. m, en tres de Ostia (BECATTI, 1961: nº 224,123,lám. XXXV; nº 187,102, lám. XXXIVy nº 334,181, lám. LVII) datados en los siglos II, III y IV respectivamente, y otro de Cirencester (NEAL, 1981,66). Este motivo, según Lavagne (RECUEELIII-1,117) derivado del opus sectile, experimenta perduración considerable, apareciendo incluso en el último cuarto del s. VI en Grado.

\section{$N^{o}$ 4. Mosaico de esquema a compás}

Frente a lo que es habitual en el resto de los mosaicos de El Ruedo en los que predomina la decoración geométrica, en éste se ha usado profusamente la decoración vegetal, dominando sobre la geométrica. El elemento vegetal constituye el recurso decorativo empleado para rellenar los espacios delimitados por los elementos geométricos. Este mosaico se encuentra en la estancia XXXII, a la que, al igual que la anterior, se accede directamente desde el peristilo.

La composición está presidida por un gran círculo central delimitado por un cordón polícromo con efecto de relieve, ribeteado por dos filetes simples (lám. VII). En el centro de este círculo, otro más pequeño decorado con una flor de ocho pétalos: cuatro lanceolados alternando con otros cuatro con volutas. Alrededor de la flor central, un motivo de aspa polícroma de doce brazos completa la decoración (lám. VIII).

El resto del campo se decora con cuartos de círculo en los ángulos y arcos entre ellos. Tanto unos como otros están circunscritos por una trenza polícroma continua de dos cabos. El conjunto de la composición genera un octógono de lados curvos cuyos vértices interiores se decoran con pequeños pétalos.

En el interior de los cuartos de círculo se inscribe un triángulo formado por una línea de meandros divididos con fracciones imbricadas y polícromas. A su vez en su interior se representa una porción de una flor muy similar a la que aparece en el centro del pavimento, constituida por una hoja con volutas en el centro, y dos lanceoladas a los lados. El espacio entre el cuarto de círculo y el triángulo se decora con una hoja de hiedra con volutas. Por su parte, el interior de los arcos de circunferencia de los laterales también se decora con elementos vegetales, en este caso se trata de grupos de tres hojas de laurel con volutas.

Finalmente, la composición concluye con un doble marco: el primero constituido por un filete doble y el otro por una trenza de tres cabos continua y polícroma.

A diferencia de otras estancias colindantes a ésta, aquí no se incluye ningún esquema complementario en la zona de la puerta, quedando esta sólo con teselas en blanco. 
Volvemos a encontrar en este mosaico de nuevo una rica policromía, utilizándose el color negro básicamente para el diseño de los distintos motivos. Para las hojas se utiliza ocre, salmón y marrón. Para el esquema central de aspas se emplea blanco, amarillo, salmón, ocre, marrón, rojo y verde en gradación descendente para dar aspecto de movimiento. Las trenzas presentan marrón y ocre la de dos cabos y amarillo, marrón y gris la de tres. En el cordón se usa ocre y marrón y en los meandros fraccionados amarillo, ocre, marrón y gris.

Las dimensiones totales del pavimento son $400 \mathrm{~cm}$. de lado, formando un cuadrado de dimensiones muy similares a los mosaicos 2 y 3 . El circulo central alcanza los $220 \mathrm{~cm}$. de diámetro máximo, mientras que el círculo con flor central inscrito en su interior mide 65 $\mathrm{cm}$. de diámetro mayor. Los cuartos de círculo de los ángulos miden $115 \mathrm{~cm}$. de radio y el triángulo interior $85-90 \mathrm{~cm}$. por $125 \mathrm{~cm}$. de lado.

El esquema de este mosaico puede incluirse en la composición conocida como "esquema a compás", aunque con algunas variantes sobre el modelo original (12). Este canevás tiene su origen en la adaptación de modelos arquitectónicos al diseño de mosaicos, proceso muy habitual en la creación de cartones. Consiste en la imitación de un techo con bóveda circular decorado con pintura mural (BLAKE, 1936:123; FERNANDEZ GALIANO, 1980:46); como resultado de ello, el mosaico presenta un círculo en el centro, cuartos de círculos en los ángulos y entre ellos, semicírculos adosados a los laterales.

El origen de este motivo está en Italia, desde donde se difunde hacia las provincias. básicamente hacia la zona occidental. En la Bética se ha documentado un conjunto bastante homogéneo de mosaicos que desarrollan esta composición en su concepción original, y que han permitido incluso identificar la actividad de una escuela musivaria en esta zona a partir de época de Adriano (FERNANDEZ GALIANO, 1980:53). La amplia y rápida difusión del esquema por gran parte del imperio, trae consigo su progresiva complicación y adaptación, incorporando elementos nuevos y dando lugar a variantes del esquema original. El caso que aquí nos ocupa, con sensibles cambios sobre el modelo canónico, formaría parte de estas variaciones, que en Italia empiezan a generarse ya en el s. I.

Por su parte, el motivo de cortina o aspas se puede encontrar en algunos pavimentos con decoración a compás, en Rocafort de Vallbona (CORPUS VIII, n² 24,23-24, lám. IX) de finales del siglo IV o inicios del V; en Bulla Regia (HANOUNE, 1980:91 -92, fig. 180185) de mediados del s. III y en Sicilia (VOZA, 1984:7-8). Formando parte de otras composiciones lo encontramos en la villa de El Romeral en Lérida (CORPUS VIII, nº 7,1617, lám. 4) fechado en la segunda mitad del s. IV, en Utica (ALEXANDER-ENNAIFER, 1974: 74-75, lám. XLI) de entre los dos primeros siglos de la era; en Bulla Regia (HANOUNE, 1980:12, fig. 37-41) datado en el s. IV; en Thuburbo Majus (ALEXAN-

(12) Sobre este diseño y su difusión en Hispania puede consultarse la obra de D. Fernández Galiano (1980: 35-64), con bibliografía al respecto. 
DER, 1980:95-97, láms. XXXVII-XXVIII) de principios del s. III; en Bergheim (RECUEIL 1-3, no 427 A, 149 ss., láms. XCV-XCVIII) del segundo cuarto del s. II; en Valentine (RECUEILIV-1, n 60,70 ss., láms. XX-XXII) de finales del s. IV y en Piazza Armerina (CARANDINI, 1982:164-165, lám. XX-47) inscrito en cuadrados enlazados y fechado en época de Constantino.

Con este pavimento concluye el conjunto de mosaicos completos conservados en El Ruedo. Los restantes han aparecido fragmentados, muy deteriorados, y de otros se han recuperado tan sólo pequeños fragmentos.

\section{$N^{\circ}$ 5. Mosaico con cuadrados entrelazados y cuadrilóbulos de peltas}

Este pavimento, situado en la estancia XIX, se encontró en muy mal estado presentando grandes lagunas provocadas en parte por la realización de labores agrícolas. A pesar de ello, los fragmentos recuperados permiten reconstruir el esquema compositivo casi en su totalidad.

En este caso el mosaico no adopta forma cuadrada sino rectangular. Los lados menores se decoran con una banda de roleos monocromos (lám. XIII) mientras que los lados mayores se presentan sin orla.

La composición está presidida por un cuadrado de grandes dimensiones formado por un doble marco: el exterior constituido por una banda de dientes de sierra dentellados en oposición de colores y el interior por una trenza de dos cabos continua y polícroma. En el interior se diseñan dos cuadrados entrelazados, que generan un octógono interior y ocho triángulos adosados al exterior. El trazo se realiza mediante dos trenzas de dos cabos polícromas, una para cada cuadrado. Se han recuperado restos de algunos de los triángulos, cuyo interior se decoró mediante triángulos superpuestos polícromos. Por su parte, el octógono central está casi perdido. Dentro de él sólo se conservan escasos restos de una banda circular de guiloches ancho con centro recto y polícromo (lám. XII), que a su vez albergaba en su interior un motivo desconocido del que no se ha conservado rastro alguno. El espacio comprendido entre los vértices del cuadrado mayor y la estrella central se completa diseñando una hoja con volutas, limitada por una trenza doble que conecta con la del marco exterior.

El resto de la decoración se completa mediante una franja situada al sur del cuadrado, con una composición a base de cuadrilóbulos de peltas (lám. IX). De ellos no se conserva ninguno completo aunque existen fragmentos suficientes para reconstruir el esquema. El cuadrilóbulo se sitúa alrededor de un cuadrado recto diseñado a base de una línea dentellada con dentículos de dos por tres teselas, en su interior, un filete simple circunscribe una esvástica polícroma con diagonales interiores. Adosadas a los lados del cuadrado aparecen cuatro peltas con dos pétalos dobles triangulares en su interior. En los ángulos aparecen cuatro husos tangentes polícromos, y entre los cuadrilóbulos, dos flores 
cruciformes, en aspa, polícromas (BALMELLE y otros, 1985: $\mathrm{n}^{2}$ 228-230). En el límite de esta franja con el lateral este se conservan dos cuadrados negros en cuyo interior portan otro cuadrado tangente -esta vez en blanco- con una cruz inscrita de teselas negras con centro blanco.

A pesar de que, como hemos dicho, el sector de los cuadrilóbulos está altamente alterado, es posible recomponer gran parte de la composición. Sabemos con seguridad que en total fueron dos cuadrilóbulos completos los que se diseñaron. El espacio entre ellos, excesivamente amplio, posiblemente estuvo ocupado por un círculo decorado, como es común en casos similares como los procedentes de Balazote (CORPUS VIII, $\mathrm{n}^{\circ}$ 32, 42-44, fig. 9), Ostia (BECATTI, 1961: $n^{2}$ 400, 210, lám. XLffl) o Bulla Regia (HANOUNE, 1980:13, figs. 47-48).

Respecto a los colores, para las peltas se utilizó un trazo negro relleno en amarillo; por su parte las flores en aspa y los husos se colorean ambos en rojo y marrón, mientras que las trenzas de los cuadrados aparecen en negro, morado, rojo, blanco, verde y ocre. El guiloche central presenta rojo, marrón y amarillo; las flores de los vértices rojo y gris y los triángulos inscritos en torno al octógono central rojo, marrón y gris.

Las medidas totales de algunos de los motivos se han perdido, aunque en casi todos los casos se pueden restablecer. Las dimensiones máximas del mosaico son $520 \mathrm{~cm}$. de longitud y $320 \mathrm{~cm}$. de ancho. La longitud está casi completa, faltando tan sólo el límite de la orla de roleos. Con la anchura no ocurre lo mismo ya que de ésta se han perdido al menos $50 \mathrm{~cm}$., con lo que en total sería como mínimo de $370 \mathrm{~cm}$. El cuadrado con doble marco mide $335 \mathrm{~cm}$. en la banda de dientes de sierra, y $290 \mathrm{~cm}$. en la de trenzado. Los cuadrados tangentes alcanzan $190 \mathrm{~cm}$. en el único lado conservado completo. Por su parte los cuadrados comprendidos por los cuadrilóbulos miden $70 \mathrm{~cm}$. de lado -también con un único lado conservado en su totalidad- y las peltas circundantes $32 \mathrm{~cm}$. de radio. Finalmente, los husos y las flores cruciformes alcanzan una longitud de 40 y $15 \mathrm{~cm}$. respectivamente.

El canevás central de cuadrados superpuestos puede aparecer como elemento aislado y centrando la composición, como en el caso que nos ocupa, o formando parte de composiciones más o menos complejas y continuas. En composición continua lo encontramos por ejemplo en la villa del Camino Viejo de las Sepulturas (Balazote, Alicante) (CORPUS VIII, $\mathrm{n}^{2}$ 31,40-42, fig. 8), en un pavimento del s. IV donde el campo se ha cubierto de estrellas de este tipo mediante un doble cuadriculado oblicuo. Un pavimento de Aquitania (RECUEIL IV-1, nº 140,145 ss., lám. LXXX) muestra otra variante, en este caso de la primera mitad del s. IV, en la que el motivo también cubre todo el campo con estrellas enfrentadas por las puntas. Otra posibilidad es que aparezcan varias estrellas de cuadrados tangentes, pero ni en composición continua ni ocupando todo el campo, sino como elementos complementarios. Este es el caso de los mosaicos de Rielves, Toledo (CORPUS V, 61 ss., fig. 39), fechado en el s. IV, Champuert (RECUEIL II-2, n³26,122- 
123, láms. LXVII-LXVIII), de la primera mitad del s. III d.C. y Piazza Armerina (CARANDINI, 1982:164-165, lám. XX-47) de época de Constantino.

Como elemento principal y eje central de la composición se constata en mayor cantidad de casos. En Hispania se ha documentado en Itálica (CORPUS II, n9 3, 27-28, láms. 11 -13), en un pavimento fechado en la segunda mitad del s. II o inicios del III; en el mosaico de Ibarra (CORPUS II, $\left.n^{\circ} 5,29-30,15-16\right)$, de la misma cronología que el anterior, en dos pavimentos de la Casa del Anfiteatro de Mérida (CORPUS I, $\mathrm{n}^{2} 31,42$, lám. 56B-63A; no 38, 43-44, lám. 70-71) fechados en el s. III; en dos pavimentos de Cuevas de Soria (CORPUS VI, $n^{\circ}$ 55,64-65, fig. 6 y n ${ }^{\circ} 60,69-70$, fig. 9) de finales del s. IV; en el mosaico de Diana Cazadora de Comunión (CORPUS V, nº 2,13-16, lám. 41) fechado en el s. IV; en Tarazona de la Mancha (CORPUS VIII, nº 40,55-56, lám. 40) con una ménade al interior y de nuevo del s. IV; en la villa de Baños de Valdearados (ARGENTE, 1979:59 ss.), posiblemente también con una figura femenina en el centro, datado en el s. V, y en Vilches (BLAZQUEZ y otros, 1987:257-279), del s. V avanzado.

Las estrellas de cuadrados superpuestos son particularmente frecuentes en Britania (13). Las encontramos en el mosaico de Venus de Gloucestershire (JOHNSON, 1982:46, lám. 35) del s. IV, en Sherbome (JOHNSON, 1982:55, lám. 44) con la misma cronología que el anterior, y en Woodchester (JOHNSON, 1982:37, lám. 27).

En Utica se ha documentado en un pavimento de la segunda mitad del s. II en el que el esquema se ha completado mediante estrellas incompletas de seis losanges (ALEXANDER-ENNAIFER, 1974: $\mathrm{n}^{\circ}$ 185, 30-31), y en la casa del gran oecus (ALEXANDERENNADFER, 1974: nº 157, 11-12, lám. VII), en este caso de principio del s. II. En Thuburbo Majus lo encontramos en varios pavimentos, cuatro de ellos de laprimera mitad del s. III (ALEXANDER, 1980: 17-18, láms. VI-VII; 59-60, lám. XXIV; 67-68, lám. XXVII; 122, lám. XLVI) y uno más de la primera mitad del IV (BEN ABED, 1985: 9-13, lám. II).

También se difunde este esquema en la Galia, de donde proceden dos mosaicos, concretamente de Lyon (RECUEIL II-1, nº 42,41, lám. XXI y nº 87,75, lám. LVIII), uno de época severiana y otro del segundo o tercer cuarto del s. III en los que el motivo aparece de nuevo asociado a estrellas incompletas de ocho losanges. Lo encontramos además en Aquilea (BLAKE, 1936: lám. XXXI), en un mosaico de la primera mitad del s. III, y en Colonia (PARLASCA, 1959:78 ss., lám. LXVI) y Tréveris (PARLASCA, 1959:33, lám. XXXIV), fechados ambos en torno al 220. De Tréveris procede otro más, fechado esta vez a mediados del s. III (HELLENKEMPER, 1984: 340-342, fig. 5).

El uso de los cuadrados superpuestos se generaliza a partir del s. I, aunque es durante los siglos II y III cuando alcanza un auge considerable (CORPUS V, 72), perviviendo hasta época tardía.

(13) El estudio del desarrollo del motivo en Gran Bretaña ha sido abordado por Cookson (1984: 53 ss.), quien aporta un amplio catálogo de mosaicos con este esquema fechados entre finales del s. III y el s. IV. 
El tema de los guiloches, representado en este caso en el interior de los cuadrados enlazados, experimenta un fuerte incremento en la segunda mitad del s. II e inicios del s. III, cronología a la que corresponden varios mosaicos de Itálica (CORPUS II, $\mathrm{n}^{\circ}$ 6, 30, lám. 17; n 3, 27, 11-12), Marbella (RODRÍGUEZ OLIVA, 1988: 160-166), Bruñel (CORPUS m, nº 48,65, 55b) y Villacarrillo (CORPUS III, nº 52,72, lám. 70). Por su parte los de Alcázar de San Juan (CORPUS V, nº 19,27, lám. 12 y 44), Jumilla (Corpus IV, nº 56,64, lám. 22; no 85,78, lám. 25) y Clunia (FERNANDEZ GALIANO, 1980: fig. 4) se fechan ya a fines del s. III o comienzos del IV.

En lo que se refiere a los cuadri lóbulos de pellas, constituyen un canevás muy común en los mosaicos hispanos. Se ha documentado en Itálica (CORPUS I, nº 11,36, lám. 30) en un pavimento de fines del s. II, utilizado como motivo aislado; en el Cortijo del Alcaide (CORPUS III, $\mathrm{n}^{\circ} 27 \mathrm{~A}, 48$ ), de Córdoba como el caso que nos ocupa; en la villa de los TorrejonesdeYecla(RAMALLO,1985:nº118,149-151,fig.30,láms.LXXIV-LXXVII y CORPUS IV, $\mathrm{n}^{\circ}$ 68, 68 ss., lám. 26) de la primera mitad del s. IV, en el que los cuadrilóbulos se unen unos a otros mediante peltas; en Mérida (CORPUS I, $\mathrm{n}^{\circ}$ 14,33-34, lám. 24b-25) del s. IV; en Vejer, Cádiz (CORPUS IV, n 50,53-56, lám. 41), con hojas fusiformes en los vértices de los cuadrados formando cuadnpétalas y de la misma cronología que el anterior; en los Cipreses, Jumilla (CORPUS IV, nº 79,73, láms. 31 -33), de mediados del s. IV y de nuevo con fusiformes en los vértices, al igual que el procedente de la villa romana del Camino Viejo de las Sepulturas, Balazote (CORPUS VIII, n 32,4244, lám. 13 y 28), en el que también aparecen las ruedas de peltas y cuya ejecución se data en el s. IV. De esta villa precedía otro testimonio, ya perdido, en el que se repetía el mismo motivo y que ofrecía la misma datación. De Córdoba procede otro caso, el mosaico de las cuatro estaciones (CORPUS III, nº 19,36-38, láms. 22-23), de nuevo con husos en los extremos y fechado en la segunda mitad del s. IV. Un último mosaico sería el procedente de Elche (PALOL, 1967:201 ss.) de la segunda mitad del s. IV al igual que el anterior.

En el Norte de África se repite en el mosaico del Asinus Nica de Djemila (BLANCHARD, 1970: 97 ss., láms. XXIII-XXVI) de comienzos del s. V. En Bulla Regia encontramos tres pavimentos (HANOUNE, 1980:13, figs. 47-48; 56-57, láms. 417-418; 38-39, láms. 73-76), dos de ellos con husos y el tercero con un único cuadrilóbulo en el centro de la composición, fechado en el s. IV (14).

En Ostia se conserva en dos mosaicos. En uno de ellos, fechado entre finales del s. III o inicios del IV, se emplea como elemento complementario (BECATTI, 1961: $\mathrm{n}^{\circ}$ 421, 223, lám. LXIII), y en el otro, de la segunda mitad del s. III (BECATTI, 1961: nº 400,210, lám. XLIII), como motivo continuo, en blanco y negro y con círculos dentados en los espacios intermedios.

De Cerdeña proceden dos testimonios más (ANGIOLILLO 1981:138-139, lám. XX

(14) Otros paralelos del norte de África pueden confrontarse en la obra de S. Ramallo (198S: 125). 
y 155, lám. XII y XLIV), uno de finales del s. II o inicios del III, y el otro de mediados del III.

La decoración a base de cuadrilóbulos de peltas es muy abundante en pavimentos de los siglos III y IV, perviviendo incluso en época medieval al menos como elemento decorativo, como demuestra su presencia en el códice De institutione arithmetica de Boecio (BECATTI, 1961: 210). Su difusión se centra preferencialmente en el norte de África, zona geográficamente cercana a laque aquí nos ocupa. Los ejemplos africanos se caracterizan porque, al igual que el de Almedinilla, suelen presentar husos tangentes en los vértices.

Finalmente, y para concluir el estudio de este mosaico, sólo hacer alusión al tema de la esvástica. Este, muy usado como complemento en el s. III, constituye un motivo decorativo de sobra conocido desde antiguo, de amplia difusión geográfica y que posiblemente pasa a los mosaicos a través de la cerámica (OVADIAH, 1980:149).

Debido a su prolongada aplicación en la musivaria y a su carácter complementario, sólo cabe citar algunos ejemplos a modo ilustrativo. En la Galia la encontramos en Orange (RECUEILIII-1, $\mathrm{n}^{\circ}$ 45,60 ss., lám. 13) de mediados del s. I, en Cavaillon (RECUEILIII1, n⿳a 75,77-78, lám. XXIII), Saint-Paul-Trois-Chateaux (RECUEIL III-1, nº111,105 ss., láms. XL-XLI) y Apt (RECUEIL III-1, nº 199,145 ss., láms. LIV-LVI) de 130-150 d.C. los tres y en Auriébat (RECUEIL IV-1, nº 102,105 ss., láms. XLIV-XLVI) del s. IV o algo posterior, generalmente inscrita en cuadrados tangentes.

En Ostia aparece en un pavimento con husos tangentes en el edificio de los augustales (BECATTI, 1961: no 420,222-223, lám. XLII) de finales del s. III o inicios del IV. Como elemento central e inscrita en un cuadrado lo encontramos en otro pavimento ostiense, este de mediados del s. II (BECATTI, 1961: nº 18,17-18, lám. XIX). En la dormís de los Dioscuros (BECATTI, 1961: nº 218,123, lám. XLVII) se representa en el interior de una rueda de peltas, ocupando el lugar del nudo de Salomón, fechado en la segunda mitad del s. IV. Por último, en otro pavimento del edificio de los augustales (BECATTI 1961: $\mathrm{n}^{\circ}$ 421,223 , lám. LXIII) fechado también a finales del s. III o inicios del s. IV.

En el norte de África el modelo es más similar al empleado en El Ruedo, documentándose habitualmente en policromía y con diagonales en el interior de los brazos de la esvástica. A este tipo corresponden los mosaicos de la casa de Catón de Utica (ALEXANDER-ENNAIFER, 1974: no 201 A, 46-47, láms. XXXI-XXXII), probablemente de finales del s. III, de Tipasa (DUVAL, 1975: lám. XXXI2) de la segunda mitad del s. IV o de la primera mitad del V, y de la basílica de Grado (MIRABELLA, 1975: lám. LXVII). Su aparición también en Piazza Armerina (CARANDINI, 1982: 164-165, lám. XX-47) en época de Constantino, sirve de ejemplo para demostrar la difusión de esta variante también fuera del área africana. 
En la estancia XXXII se conservan escasos restos del pavimento musivo que, en otro momento, decoró la habitación. Sólo ha llegado hasta nosotros un pequeño fragmento situado en el ángulo noroeste de la estancia que ocupa aproximadamente un sexto de su superficie total. A pesar de que el esquema compositivo está casi perdido, es posible reconocer algunos elementos y recomponer otros.

El mosaico presentaba en el extremo norte una banda decorada a base de semicírculos secantes formando ojivas y escamas, en oposición de colores. Del esquema principal sólo se ha recuperado un fragmento de reducidas dimensiones. Posiblemente representaba una estrella de ocho puntas a base de dos cuadrados enlazados que generan un octógono interior y ocho triángulos adosados. El trazo de los cuadrados se efectuó mediante dos trenzas de dos cabos. La estrella se halla inscrita en un círculo formado por un filete simple, con el que conectan sus puntas. El espacio comprendido entre la circunferencia exterior y las puntas de la estrella se decoró mediante un triángulo polícromo de un lado curvo. Al igual que en el caso del mosaico anterior, aquí tampoco se ha conservado ningún vestigio de la decoración del interior del octógono central.

Este esquema principal se encontraba ligeramente basculado hacia la entrada de la estancia, dejando un espacio libre en el este en el que no se ha conservado ningún vestigio decorativo. El resto de la decoración se completa incluyendo en los vértices del cuadrado principal una pelta terminada en volutas (15).

Para las trenzas de los cuadrados tangentes se han empleado los colores marrón y salmón. En el interior de la pelta conservada se emplean el ocre y salmón. Por último, el espacio comprendido entre el círculo y las puntas de la estrella se completa sólo con salmón.

Las dimensiones totales de los distintos motivos y del mosaico en conjunto se han perdido prácticamente en todos los casos, aunque la reconstrucción hipotética del pavimento permite ofrecer unas cifras aproximadas y orientativas. El rectángulo total medía aproximadamente unos $600 \mathrm{~cm}$. de largo y 360 de ancho. La banda de semicírculos secantes alcanzaba unos $20 \mathrm{~cm}$. de anchura. El círculo central medía unos $250 \mathrm{~cm}$. de diámetro, mientras que los cuadrados de su interior superarían en poco los $150 \mathrm{~cm}$. de lado. Para concluir, la pelta del vértice presenta una altura de $30 \mathrm{~cm}$.

Para el tema de los cuadrados superpuestos simplemente remitimos a lo y a dicho para el mosaico anterior. De los escasos motivos restantes conservados, cabe detenerse en la orla de semicírculos secantes y tangentes formando ojivas y escamas (BALMELLE y otros, 1985: $\mathrm{n}^{9}$ 49). Esta decoración se emplea habitualmente para confeccionar la orla que delimita la zona decorada; se desarrolla de forma considerable a partir del s. II en los

(15) De estas pellas solo se ha recuperado la correspondiente al ángulo noroeste, aunque siguiendo la organización aparentemente simétrica del mosaico es probable que en todos los ángulos se incluyese una. 
mosaicos itálicos en blanco y negro (BLAKE, 1936:83 ss.), alcanzando amplia difusión en época tardía (PALOL, 1967: fíg. 92, lám. 36).

Orlas con esta decoración se diseñan en Hispania en el mosaico de Neptuno de Itálica (BLANCO-LUZON, 1974: lám. III-IV), o en otro fragmentado también de Itálica (CORPUS I, $\mathrm{n}^{\mathrm{a}}$ 13,33, lám. 24a) asociado a ruedas de peltas y fechado a fines del s. III o inicios del s. IV. En un pavimento emeritense (ALVAREZ, 1990: lám. 26) se ha fechado en el s. IV. En Elche se representa en el mosaico de Galatea (CORPUS IX, n 17,36-37, fig. 17) fechado en el s. IV, en el que tanto las ojivas como las escamas se dejan en blanco. En un mosaico geométrico de Comunión (Cabriana, Álava), aparece igual que el anterior, con ojivas y escamas en blanco, siendo también del s. IV (CORPUS V, $\mathrm{n}^{\circ} 3,16$, fig. 4), la única diferencia es que en éste los semicírculos sólo se incluyen en una banda en uno de los laterales. En un mosaico de peces de la villa del Camino Viejo de las Sepulturas en Balazote (CORPUS VIII, $n^{\circ} 31,40-42$, fig. 8) se emplea en oposición de colores, aunque invertido, de nuevo fechado en el s. IV. También se representan en oposición de colores los semicírculos de la orla que rodea el mosaico del triunfo de Dionysos de Ecija (CORPUS rv, nº 1,13-19, láms. 1-2), cuya cronología se establece en época severiana. De la misma época es el mosaico de los trabajos de Hércules de Liria (CORPUS IX, nº 26,4245, láms. 22-25), de nuevo con las ojivas de la orla en oposición de colores.

En Ostia encontramos igualmente representaciones de este motivo en la domus de la gorgona (BECATTT, 1961:25, lám. LXXII) y en el edificio de los augustales (BECATTI, 1961: lám. XLII), en ambos en oposición de colores y con cronología de fines del s. III o de la primera mitad del s. IV.

En Galia se emplea en dos pavimentos de Souzy-la-Briche, en uno en policromía, de finales del s. IV o algo más tardío (RECUEIL II-3, n² 483, 115 ss., láms. LXXXIVLXXXVII), y en el otro en oposición de colores y datado en el s. IV (RECUEIL II-3, $\mathrm{n}^{\circ}$ 489,125 ss., láms. XCIV-XCVII).

Según Darmon (RECUEIL II-3,125 ss.), este motivo es usado con poca frecuencia en Galia del Norte. En Germania, con ejemplos en blanco y negro datados en los siglos III y IV, es también poco frecuente. En Suiza es más abundante, al igual que en Italia donde la mayoría de los ejemplos son tardíos. En África se da un uso muy abundante de este motivo de borde tanto en bicromía como en policromía con alternancia de colores.

\section{$N^{o} 7$. Mosaico con ondas de peltas}

De este mosaico, ubicado en la estancia XVII, se conservan escasos restos limitados a varios fragmentos en los ángulos. El resto del pavimento, del que no queda vestigio alguno, se perdió ya de antiguo. En un momento identificable con la tercera fase constructiva de la villa (CARRILLO, 1990: 93), se construye en la zona norte de la estancia una estructura de ladrillo de forma ultrasemicircular -stibadium-, recubierta por 
una capa de opus signinum alisado y pintado con imitaciones de mármol moteado. En este mismo momento se añade también una capa de opus signinum al suelo, amortizando el mosaico, ya en muy mal estado de conservación (lám. XV).

Respecto al esquema compositivo conservado, la mayor parte corresponde a la zona periférica, donde se incluye una orla formada por un filete doble que traza una línea de meandros con codos cuadrados. En el interior de cada codo se incluye una florecilla en aspa oblicua y monocroma. Como límite de este marco se introduce un filete recto monocromo (Lám. XIV).

En el ángulo noroeste aparecen restos de una decoración constituida por filas de cuadrados diseñados mediante un filete negro, en cuyo interior se incluye una cruz bícroma de cinco teselas. Los cuadrados van unidos con sus inmediatos por segmentos.

Por otra parte, en el ángulo sureste se conservan vestigios de una composición diferente: ondas de peltas compuestas (BALMELLE y otros, 1985: $\mathrm{n}^{9} 249$ ), con los intervalos cargados con cuadrados dentellados tangentes, y con las peltas muy apuntadas. Esta decoración quedaba limitada por una banda con trenza de dos cabos de la que se ha localizado un pequeño testimonio.

La mayoría de los motivos decorativos de este mosaico se han representado en blanco y negro. En la onda de peltas, los cuadrados intermedios y la trenza se emplean rojo, ocre, blanco y azul.

Las dimensiones totales de la estancia son doce metros y medio por siete, siendo la más amplia de las excavadas. Sin embargo, de su mosaico se conservan escasos restos que apenas suponen una décima parte del espacio pavimental. Sólo se conocen las medidas de algunos de los elementos decorativos, así por ejemplo, los meandros de la orla forman cuadrados de $35 \mathrm{~cm}$. de lado. Los cuadrados del campo, algo más pequeños, alcanzan los $24 \mathrm{~cm}$. de lado. Por su parte, las peltas, que presentan unos $18 \mathrm{~cm}$. de altura, se caracterizan porque no adoptan forma semicircular sino que se presentan muy apuntadas en el centro. Finalmente, las crucecitas polícromas intermedia, constituyen cuadrados de $10 \mathrm{~cm}$. escasos de lado.

El tema de codos cuadrados en orla lo podemos encontraren Pont d'Ancy (RECUEIL 1-1, no 81,54 ss., láms. XXVHI-XXX), fechado en la primera mitad del s. III y en tres pavimentos de Bulla Regia (HANOUNE, 1980:13, figs. 44-46; 41,figs.98-100y91 ss., fig. 182) de entre mediados del s. III y el s. IV, en los que, al igual que en El Ruedo, se incluyen florecillas en aspa en el interior de los codos.

Por su parte, el tema de filas de cuadrados aparece con un tratamiento muy similar al correspondiente al Ruedo en otro mosaico, también de Córdoba, datado en la segunda mitad del s. II (CORPUS III, nº 33,54, lám. 42). Algunas variaciones sobre el esquema presenta un mosaico de Ecija (CORPUS IV, n 11, 30, lám. 10), que ofrece la misma cronología que el anterior. Otros paralelos, ya no hispanos, son los procedentes de Lyon (RECUEIL, 11-1,35-36, láms. XVII-XIX) de baja época, de Ostia(BECATTI, 1961:192, 
lám. XXXIX) de la primera mitad del s. II, y deUtica(ALEXANDER-ENNAIFER, 1974: 45,fig.49).

\section{$N^{o}$ 8. Mosaico de husos bicromos}

En la galería norte del peristilo -espacio IX- se han podido recuperar los restos en muy mal estado de un mosaico del que se conserva parte de la orla y parte del campo. En lo que respecta a la orla, estaba decorada con un esquema vegetal a base de roleos con hojas de hiedra trazados mediante un fílete negro. En el campo, se observa una composición ortogonal de círculos secantes (lám. XVII) dejando entrever cuadripétalos y formando cuadrados cóncavos, con un ápice en las intersecciones y con florecilla monocroma inscrita en los cuadrados (BALMELLE y otros, 1985: n 237-241). Posiblemente este diseño cubría la totalidad del pavimento del peristilo, sin embargo, la escasa superficie documentada nos impide confirmar esta posibilidad.

La mayor parte del espacio conservado es blanco-negro. Tan solo el interior de los husos presenta parte de su superficie en rojo.

Tampoco aquí se conservan las dimensiones totales de la mayoría de los elementos. Únicamente podemos aportar los datos correspondientes a los husos, que alcanzan casi 30 $\mathrm{cm}$. de longitud y $10 \mathrm{~cm}$. de anchura.

El tema de los husos tangentes, de origen muy antiguo, constituye uno de los motivos decorativos más difundidos en la mu si varia romana, perviviendo hasta época tardía. Para Ovadiah (1980:157 ss.), la alta diferencia cronológica con paralelos en otras artes, parece indicar que la aplicación del motivo a los mosaicos es creación independiente de sus artesanos. Debido a su amplia difusión espacial y cronológica sólo cabe citar, a modo ilustrativo, los paralelos más cercanos y similares, evitando una relación, por otra parte muy extensa, de los casos y tipos conocidos. En Córdoba lo encontramos en la Corredera (CORPUS III, nº 9,25-26, lám. 9) fechado en la primera mitad del s. III; en las calles Cruz Conde (CORPUS III, nº 15,33-34, lám. 19) y Tejares (CORPUS III, nº 17,35, lám. 83) de los siglos II y III-IV respectivamente; en el Cortijo del Alcaide (CORPUS III, $\mathrm{n}^{\circ} 29$, 48), también del s. II, y en la villa de Cabra datado a comienzos del s. III (CORPUS III, $\mathrm{n}^{9}$ 31,49-50, fig. 17). De un momento anterior es el pavimento de la Quintanilla (RAMALLO, 1985:92 ss.), fechado en el s. I o en la primera mitad del siglo II, en el que, siguiendo el gusto norteafricano, se representan los husos en denticulado. En Ostia (BECATTI, 1961:106, lám. XLI) lo encontramos en la segunda mitad del s. I, frente a varios de Bulla Regia (HANOUNE, 1980: 7-8, figs. 11-12; 9-10, figs. 20-21 y 39, figs. 80-81) que alcanzan ya el s. IV. 
Muy cerca del anterior se conserva otro pavimento, igualmente en muy mal estado y de características muy similares. Al igual que en el primero, este otro también presenta un marco formado por roleos con hojas. En el campo se conservan los restos de cuatro husos que formaban parte de una composición de círculos secantes generando cuadripétalos y cuadrados cóncavos. En el interior de estos cuadros también se incluye una florecilla en aspa monocroma. Se han conservado algunos fragmentos del campo donde se observa una decoración diferente al cuadriculado de husos. El mal estado de dichos fragmentos y su escasa superficie impiden reconocer el motivo elegido.

$\mathrm{Al}$ igual que en el caso anterior el único vestigio de color conservado corresponde al interior de los husos, divididos en cinco franjas perpendiculares. De ellas, las extremas, de mayor anchura, se decoran con rojo, las intermedias en salmón y la central en blanco.

A pesar de que el mosaico está muy fragmentado, la disposición de los fragmentos conservados ha posibilitado la documentación de las distancias totales. El pavimento abarcaba la totalidad del pasillo, de unos $270 \mathrm{~cm}$. Las orlas laterales ocupaban $50 \mathrm{~cm}$., quedando libres $170 \mathrm{~cm}$. que quedaban reservados para el campo.

\section{$N^{o}$ 10. Mosaicos muy fragmentados}

Incluimos en este apartado algunos fragmentos muy deteriorados de mosaicos de los que sólo se conservan vestigios mínimos y escasos elementos decorativos. A pesar de que por su estado de conservación carecen del interés de los hasta ahora expuestos, consideramos que son elementos a tener en cuenta ya que, al menos, son el indicio que nos permite afirmar que las estancias en las que aparecen estuvieron pavimentadas con mosaico en algún momento de su ocupación.

\section{Mosaico 10.1}

Sólo contamos con una pequeña muestra de este pavimento, constituida por una franja de $30 \mathrm{~cm}$. por $15 \mathrm{~cm}$., en la que aparece una trenza polícroma de dos cabos sobre fondo oscuro. Los colores empleados son: negro, rojo, amarillo y blanco.

\section{Mosaico 10.2}

De él se conserva un fragmento de aproximadamente $30 \mathrm{~cm}$. de ancho por $40 \mathrm{~cm}$. de largo. El único esquema que se observa es una línea de postas con enrrollado múltiple en negro sobre fondo blanco. 
$\mathrm{Al}$ igual que en el caso anterior nos encontramos ante un esquema blanco-negro. Mediante un fílete doble negro se traza un ángulo que marca el límite del mosaico, en cuyo interior se entreven los restos de una pelta terminada en volutas (lám. XVIII). Posiblemente ésta formaba parte de una línea de peltas verticales afrontadas a cada lado de un rombo horizontal (BALMELLE y otros, 1985: ${ }^{\circ}$ 59). El espacio recuperado de este mosaico no excede de $70 \mathrm{~cm}$. de largo por $25 \mathrm{~cm}$. de ancho.

\section{Mosaico 10.4}

La extrema destrucción de este mosaico -sólo se conserva un fragmento de $20 \mathrm{~cm}$. de largo por $15 \mathrm{~cm}$. de ancho- nos impide aportar dato alguno sobre su decoración. No se reconoce ningún esquema en el reducido espacio decorado en negro, blanco y rojo.

Hecho significativo es la localización de este mosaico en el estanque -estancia XI-. Sin duda corresponde a una etapa anterior a éste en la que en esta zona se situaría el patio (CARRILLO, 1990:92). Su amortización en la fase siguiente para construir el estanque justifica el mal estado en que se halló.

Sin querer caer en un excesivo "africanismo" denunciado ya por D. Fernández Galiano (1984: 411), parece manifiesta la influencia norteafrícana en el conjunto de pavimentos de El Ruedo. Esta tendencia hay que ponerla en relación con la corriente que desde finales del s. III y durante el s. IV ejercen los talleres africanos en Hispania. Para interpretar la aparición de estos motivos no es preciso plantear la presencia de mosaistas foráneos, venidos posiblemente para obras de mayor envergadura, ya que la mera difusión de cartones es razón suficiente para explicar la aparición de esquemas de origen norteafricano.

Principalmente es el motivo de cuadrilóbulos de peltas el que más se aproxima a esta corriente. Este elemento, de raigambre netamente africana, se desarrolla en dicha zona sobre todo durante los siglos III y IV -especialmente durante el IV-con especial profusión de la variedad específica que se documenta en El Ruedo, con husos tangentes en los vértices. Por otra parte, en la orla de ojivas y escamas del mosaico 6 queda de nuevo patente la influencia norteafrícana de época tardía.

A pesar de que queda clara la relación, no debe pensarse en la existencia de una influencia directa o dependencia de estos mosaicos con las producciones norteafricanas. Más bien debe considerarse la presencia de motivos con este origen que, aun siendo abundantes, conviven con otros claramente vinculables a producciones de otras provincias y a creaciones propias hispanas. 
Así pues, junto a los motivos de influencia claramente africana, también se perciben otros relacionados más bien con influjos diferentes norditálicos y gálicos -por ejemplo las estrellas de losanges, muy vinculadas a los talleres rodaneses sobre todo durante los siglos II o III- o itálicos -de donde al menos en origen proceden las orlas de arquerías-.

Como ya hemos dicho, llama especialmente la atención en El Ruedo la ausencia total de motivos figurados en la decoración de los pavimentos, peculiaridad que se ratifica en la decoración parietal salvo en un caso (v. nota 2). Al respecto cabe citar la tendencia al aniconi smo y al desarrollo de la decoración geométrica, que D. Fernández Galiano (1984: 427) establece como característica principal de la corriente orientalista que experimenta la musivaria hispana desde mediados del s. IV y durante el s. V.

Por otra parte y siguiendo las conclusiones de S. Ramal lo (1985:165) para Cartílago Nova, en la decoración musiva de El Ruedo se debe entrever más bien la actividad de una serie de artistas hispanos, trabajando en las distintas villas, cubriendo las necesidades básicas de gran parte de la población. Quizás la ausencia de motivos figurados o cartones especialmente complejos confirma este carácter' 'utilitario" de los mosaicos.

La mayor parte del repertorio musivo de El Ruedo se incluye en la última gran fase constructiva de la villa, fechable en el s. IV. A ella pertenecen todos los pavimentos completos y gran parte de los fragmentados. De aquellos que están muy fragmentados, o amortizados por pavimentos de cal -estancias IX y XVII-, podemos asegurar que corresponden a la etapa anterior, ya que en parte han sido dañados por las obras de reestructuración. En esta renovación y transformación se cierra el peristilo, se construye el hipocausto en la estancia LXII y se decora todo el sector noroeste tanto con pavimentos musivos como con estucos pintados con imitaciones marmóreas. Por otra parte, en todos los pavimentos de esta etapa queda bien definido el gusto tardío del horror vacui, y aparecen todos los espacios intermedios rellenos a base de elementos geométricos y vegetales, evitando en lo posible las zonas sin decorar. 
Bibliografía

ALEXANDER, M. y ENNAIFER, M. (1974): Corpus de Mosaiques de Tunisie I. Utique II. Túnez.

ALEXANDER, M. y otros (1980): Thuburbo Majas. Les Mosaiques de la región du Forum. Túnez.

ALVAREZ MARTÍNEZ, J.M«(1990): Mosaicos romanos de Mérida. Nuevos hallazgos. Mérida.

ANDREW COOKSON, N. (1984): "Romano-British Mosaics. A reassessment and critique of some notable sytilistics affinities". BAR, British Series, 135. Oxford.

ANGIOLILLO, S. (1981): Sardinia: mosaici antichi in Italia. Roma.

ARCOS VON HAARTMAN, E. y ALVAREZ RUBIERA, A. (1988): "Análisis de la naturaleza, estructuray tecnologíadel conjunto de mosaicos de la villa romana del Cortijo Auta (Riogordo), villa romana del Cortijo Vila (Alameda) y del ninfeo romano de Carnicería de los Moros (Antequera)". Mainake, X, pp. 159-180.

ARGENTE OLIVER, J.M. (1979): "La villa romana de Baños de Valdearados (Burgos)".EAE, 100.

B ALMELLE, C. (1980): Recueil General des mosaiques de la Gaule, IV. Aquitaine, l.Partie méridionale. París.

B ALMELLE, C. y otros (1985): Le décor géométrique de la mosaique romaine. París.

BECATTI, G. (1961): Scavi di Ostia, TV. Mosaici epavimenti marmorei. Roma.

BEN ABED-BEN KHADER, A. (1985): Thuburbo Majus. Les Mosaiques de la región desgranas Thermes. Túnez.

BLANCHARD-LEMEE, M. (1975): Maisons a mosaiques du quartier central de Djemila (Cuicul). Etudes d'antiquites africaines. Aix-en-Provence.

BLANCO FREIJEIRO, A. (1978a): Corpus de Mosaicos de España, I. Mosaicos romanos de Mérida. Madrid.

BLANCO FREIJEIRO, A. (1978b): Corpus de Mosaicos de España, II. Mosaicos romanos de Itálica, I. Madrid.

BLANCO FREIJEIRO, A. y LUZON NOGUE, J.M. (1974): El mosaico deNeptuno en Itálica (Sevilla). Sevilla.

BLAKE, M.E. (1930):"The Pavements of the Román Buildings of the Republic and Early Empire". MAAR, VIII, pp. 7-159.

BLAKE, M.E. (1936): "Román Mosaics of the Second Century in Italy". MAAR, XIII, pp. 67-214.

BLAZQUEZ, J.M.(1981): Corpus de Mosaicos de España, III. Mosaicos romanos de Córdoba, Jaén y Málaga. Madrid.

BLAZQUEZ, J.M. (1982a): Corpus de Mosaicos de España, TV. Mosaicos de Sevilla, Granada, Cádiz y Murcia. Madrid.

BLAZQUEZ, J.M. (1982b): Corpus de Mosaicos de España, V. Mosaicos romanos de la Real Academia de la Historia. Ciudad Real, Toledo, Madrid y Cuenca. Madrid. 
BLAZQUEZ, J.M. y ORTEGO, T. (1983): Corpus de Mosaicos de España, VI. Mosaicos de Soria. Madrid.

BLAZQUEZ, J.M.; LÓPEZ MONTEAGUDO, G.; NEIRA JIMÉNEZ, M.L. y SAN NICOLÁS PEDRAZ, M.P. (1989a): Corpus de Mosaicos de España, VIII. Mosaicos romanos de Lérida y Albacete. Madrid.

BLAZQUEZ, J.M.; LÓPEZ MONTEAGUDO, G.; NEIRA JIMÉNEZ, M.L. y SAN NICOLÁS PEDRAZ, M.P. (1989b): Corpus de Mosaicos de España, IX. Mosaicos romanos del Museo Arqueológico Nacional. Madrid.

BLAZQUEZ, J.M. y otros (1987): "Mosaico romano de Vilches (Jaén)". AEA, 60, pp. 275-279.

CARANDINI, A. y otros (1982): Filosofiana. La villa di Piazza Armerina. Palermo.

CARMONA BERENGUER, S. (1990): "La necrópolis tardorromana de 'El Ruedo' Almedinilla. Córdoba". Anales de Arqueología Cordobesa, I, pp. 155-172.

CARRILLO DIAZ-PINES, J.R. (1990): "Técnicas constructivas en la villa romana de El Ruedo (Almedinilla, Córdoba)"'. Anales de Arqueología Cordobesa, I, pp. 81 -108.

DARMÓN, J.P. (1977): Recueil General des mosaiques de la Gaule II. Lyonnaise-3. París.

DUNBABIN,K.M.D.(19n):The Mosaics of Roman North Africa.Studies in Iconography and Patronage. Oxford.

DUVAL, N. (1975): "Observations sur l'origine, la technique et l'histoire de la mosaíque funérarie chrétienne en Afrique". La Mosaique Greco-Romaine, II. París, pp. 63 y ss.

FERNANDEZ GALIANO, D. (1980): Mosaicos hispanos de esquema a compás, Guadalajara.

FERNANDEZ GALIANO, D. (1984): "Influencias orientales en la musivaria hispánica". /// Colloquio Internazionale sul mosaico antico. Ravena, pp. 411-430.

FOUCHER, L. (1961): Découvertes archéologiques á Thysdrusen 1960. Túnez.

HANOUNE, R. (1980): Recherches archéologiques franco-tunisiennes á Bulla Regia, IV. Les mosaiques, 1. Roma.

HELLENKEMPER SALIES, G. (1984): "Nueve Rómische Mosaiken in Deustchland Beiträge zur Chronologie der 3. Jarhunderts". /// Colloquio Internazionale sul mosaico antico. Ravena, pp. 335 y ss.

HIDALGO PRIETO, R. (1990): "Esquemas decorativos pictóricos de la villa romana de El Ruedo (Almedinilla, Córdoba)". Anales de Arqueología Cordobesa, I, pp. 109124.

JOHNSON, P. (1982): Romano-British Mosaics, Haverfordwest.

LEVI, D. (1947): Antioch Mosaic Pavements, Princeton.

LANCHA, J. (1981): Recueil General des mosaiques de la Gaule, III. Narbonnaise2. París.

MAREC, E. (1958): Monuments chrétiens d'Hippone, ville épiscopale de Saint Agustín. París. 
MIRABELLA-ROBERTI, M. (1975): "Motivi aquileiesi nei pavimenti deU'arco adriatico e ella val Padana". La Mosaíque Greco-Romaine, II. París, pp. 193 y ss.

NEAL, D.S. (1981): Román Mosaics in Britain: an introduction to their schemes and a catalogue ofpaintings. Gloucester.

NOGARA, B. (1910): / mosaici antichi dei Palazzo Vaticani e del Luterano. Milán.

OVADIAH, A. (1980): Geometrics and Floráis PatternsinAncient Mosaics. Roma.

PALOL, P. de (1967): Arqueología cristiana de la España romana. ValladolidMadrid.

PARLASCA, K. (1959): Die Römischen Mosaiken im Deutschland. Berlín.

RAMALLO ASENSIO, S.F. (1985): Mosaicos romanos de Cartnago Nova (Hispania Citerior). Murcia.

RODRÍGUEZ OLIVA, P. (1988): "Los mosaicos de la villa romana de Bobadilla (Málaga)". BSAA, LIV, pp. 137-174.

SALTES, G. (1974): "Untersuchungen zu den geometrischen Gliederugsschemata rómischer Mosaiken". BJ., CLXXIV.pp. 1-178.

SMTTH, DJ. (1975): "Román Mosaics in Britain before the fourth century". La Mosaïque Gréco-Romaine, II, París, pp. 269 y ss.

STERN, H. (1957): Recueil General des mosaiques de la Gaule, I. Gaule Belgique-1. Partie Ouest. París.

STERN, H. (1960): Recueil General del mosaiques de la Gaule, I. Gaule Belgique-2. Partie Est. París.

STERN, H. (1963): Recueil General del mosaiques de la Gaule, I. Gaule Belgique-3. Partie Sud. París.

STERN, H. (1967): Recueil General des mosaiques de la Gaule, II. Lyonnaise-I. París.

STERN, H. y BLANCHAR-LEMEE, M. (1975): Recueil General des mosaiques de la Gaule, II. Lyonnaise-I. París.

VARGAS COSTA, M.L. (1983-1985):' 'Contribuiçáo oestudo de alguns dos mosaicos da villa romana de «Pisóes»". Archivo de Beja. Serie II, vol. 2, pp. 95-135.

VAQUERIZO GIL, D. (1990a): "Novedades arqueológicas en Almedinilla (Córdoba)". / Encuentros de Historia Local. La Subbética, Lucena-Cabra-Priego de Córdoba, octubre de 1989, Córdoba, pp. 61-79.

VAQUERIZO GIL, D. (1990b): "El Ruedo. Una villa excepcional en Córdoba". Revista de Arqueología, Año XI, nº 107, Marzo, pp. 36-48.

VAQUERIZO GIL, D. (1990c):' 'La decoración escultórica de la villa romana de El Ruedo (Almedinilla, Córdoba)". Anales de Arqueología Cordobesa, I, pp. 125-154.

VOZA, G. (1984): "Aspecti e problemi di nuovi monumenti d'arte musiva in Sicilia". /// Colloquio Internazionale sul mosaico antico. Ravena, pp. 5 ss. 


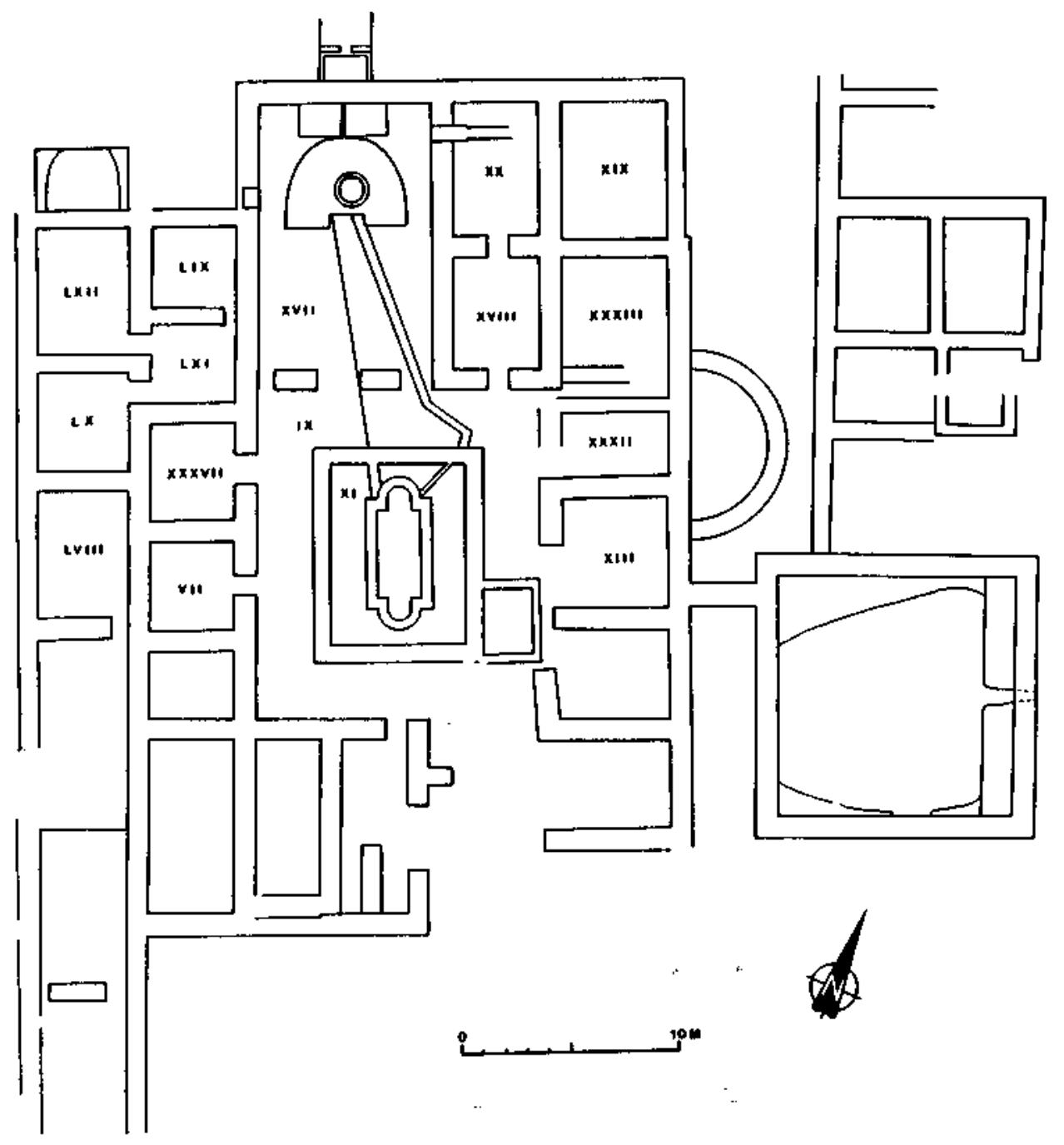

Fig. 1. Planta de la villa de El Ruedo con la identificación de las estancias. 


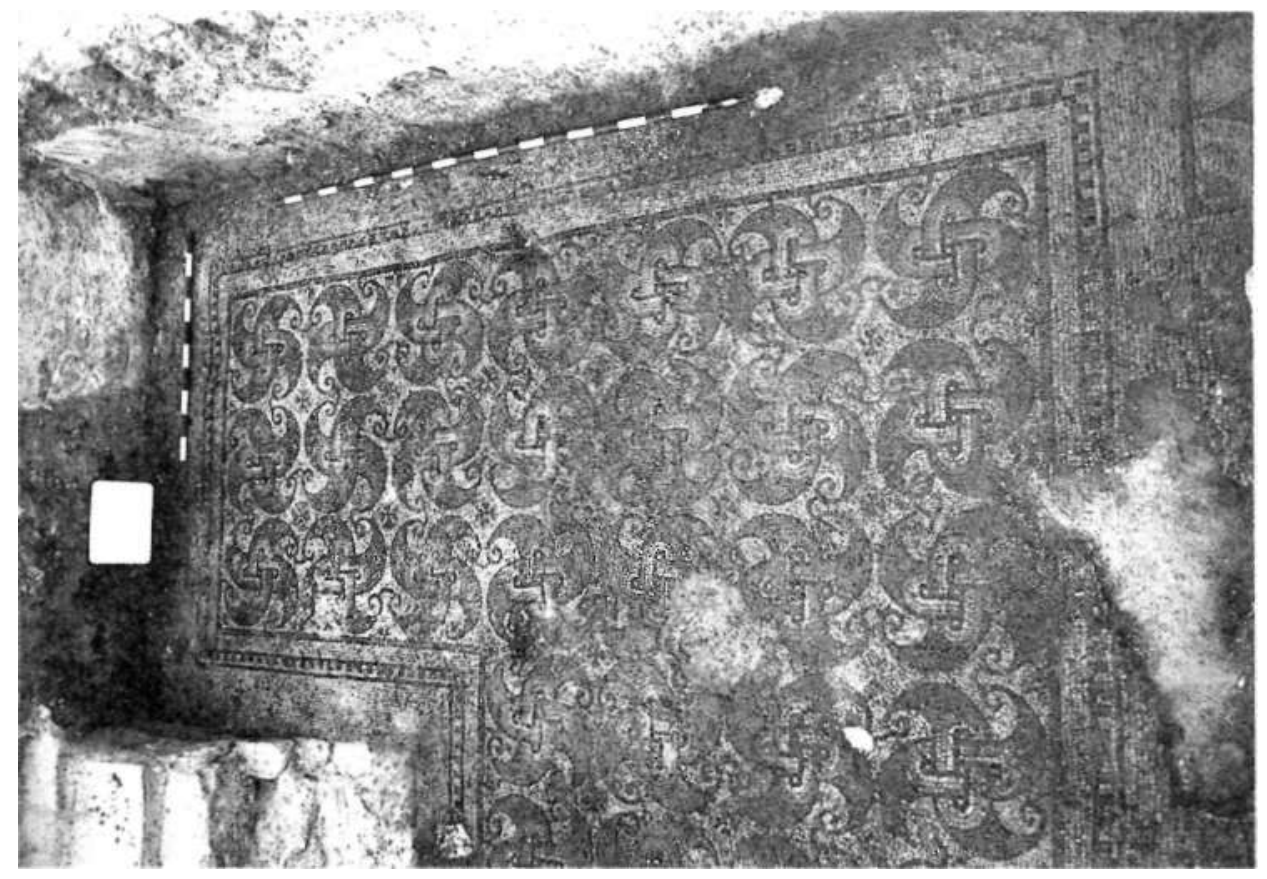

Lám. I. Mosaico de ruedas de peltas.

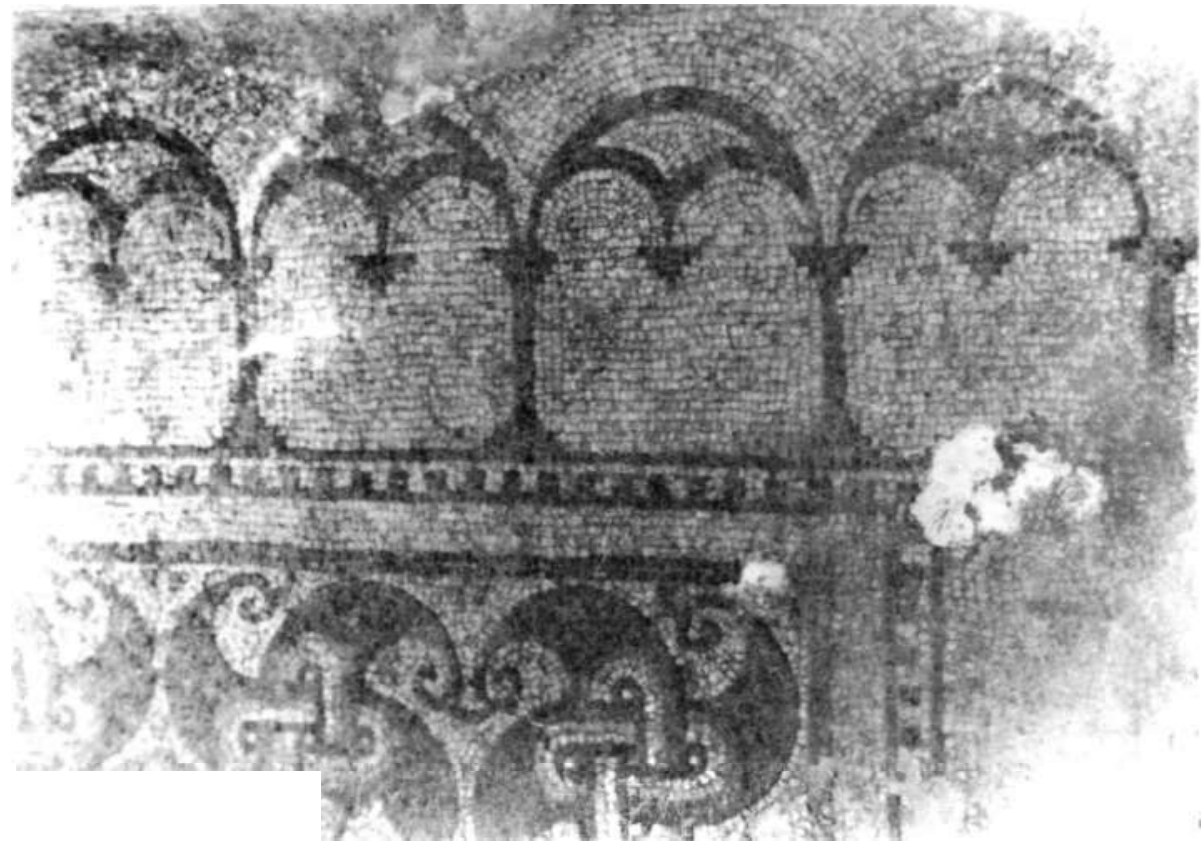

Lám. II. Detalle de la arquería de peltas (mosaico 1). 


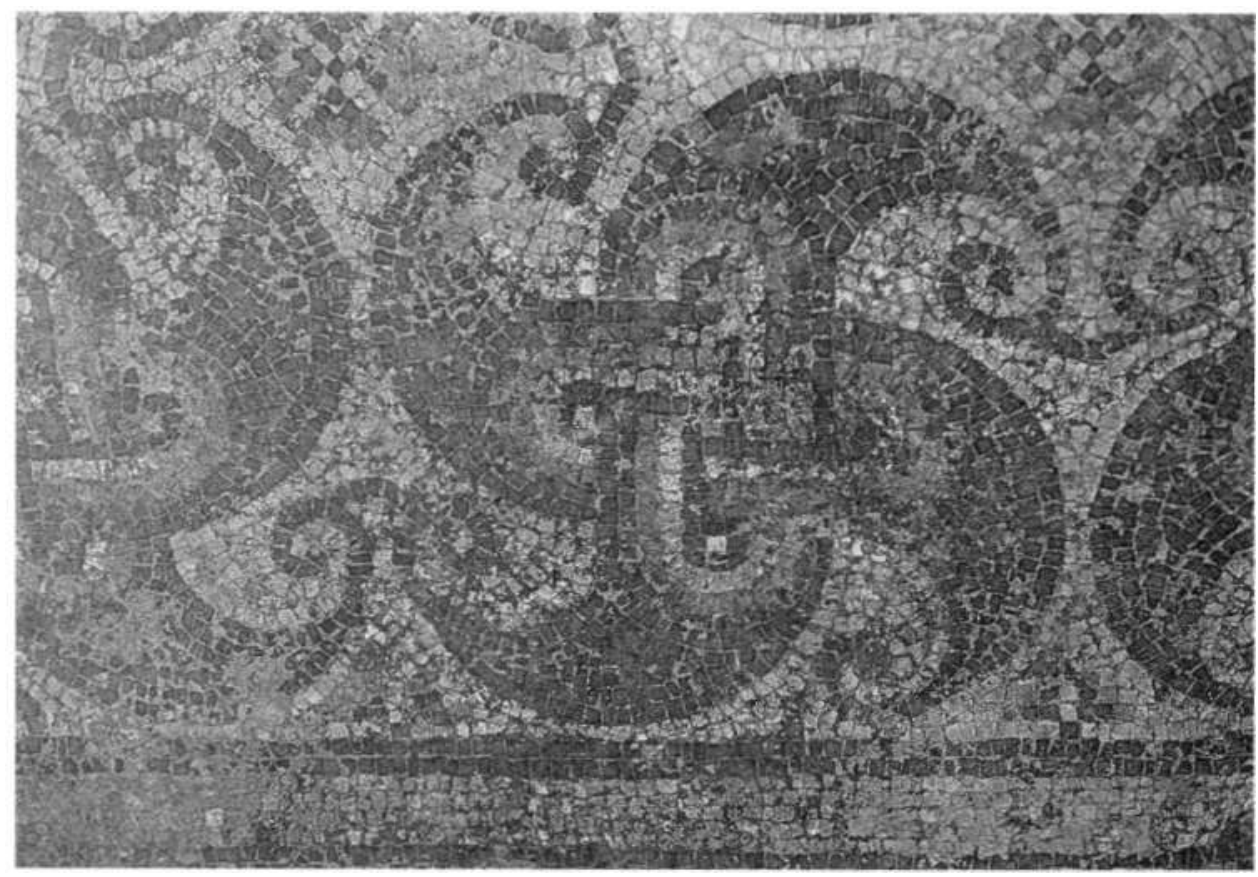

Lám. III. Rueda de peltas (detalle).

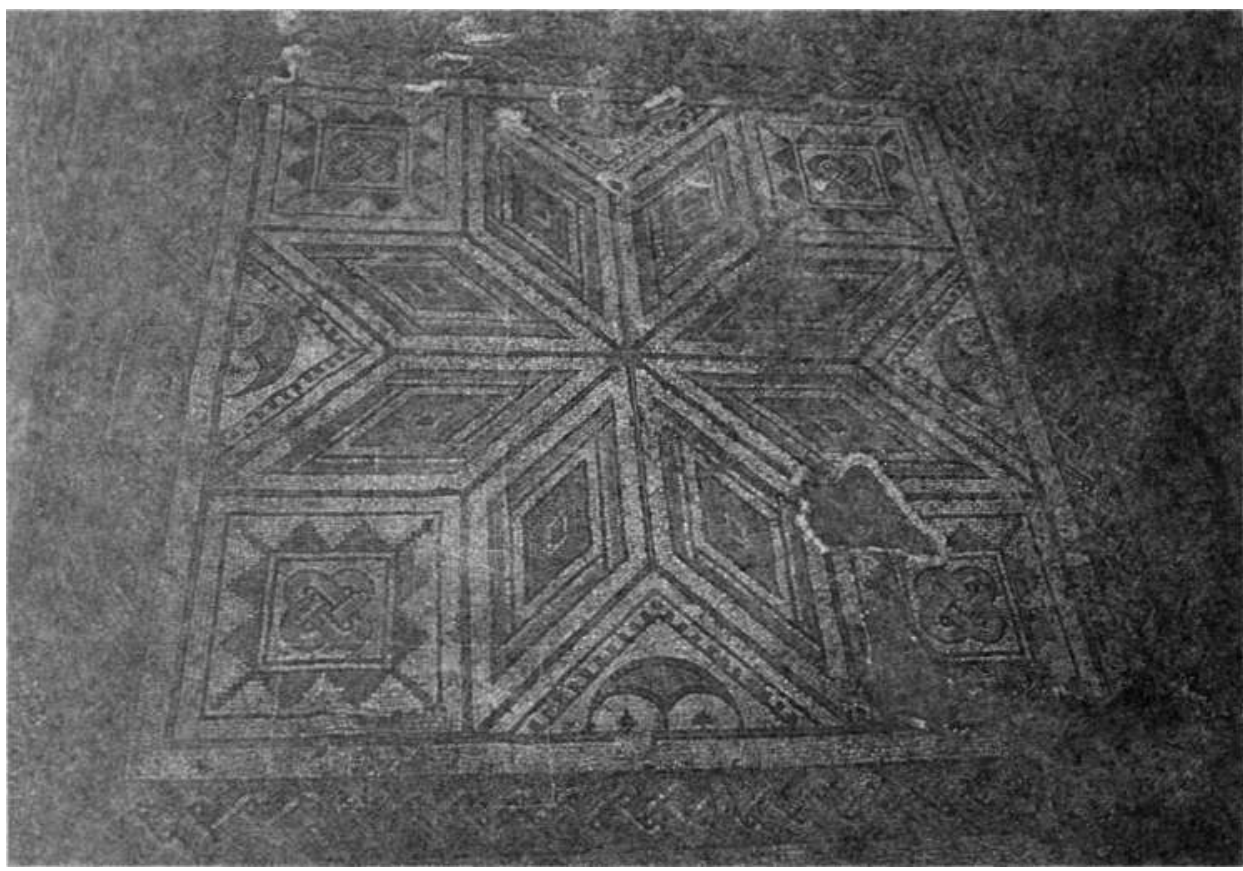

Lám. IV. Mosaico con estrella de ocho losanges. 


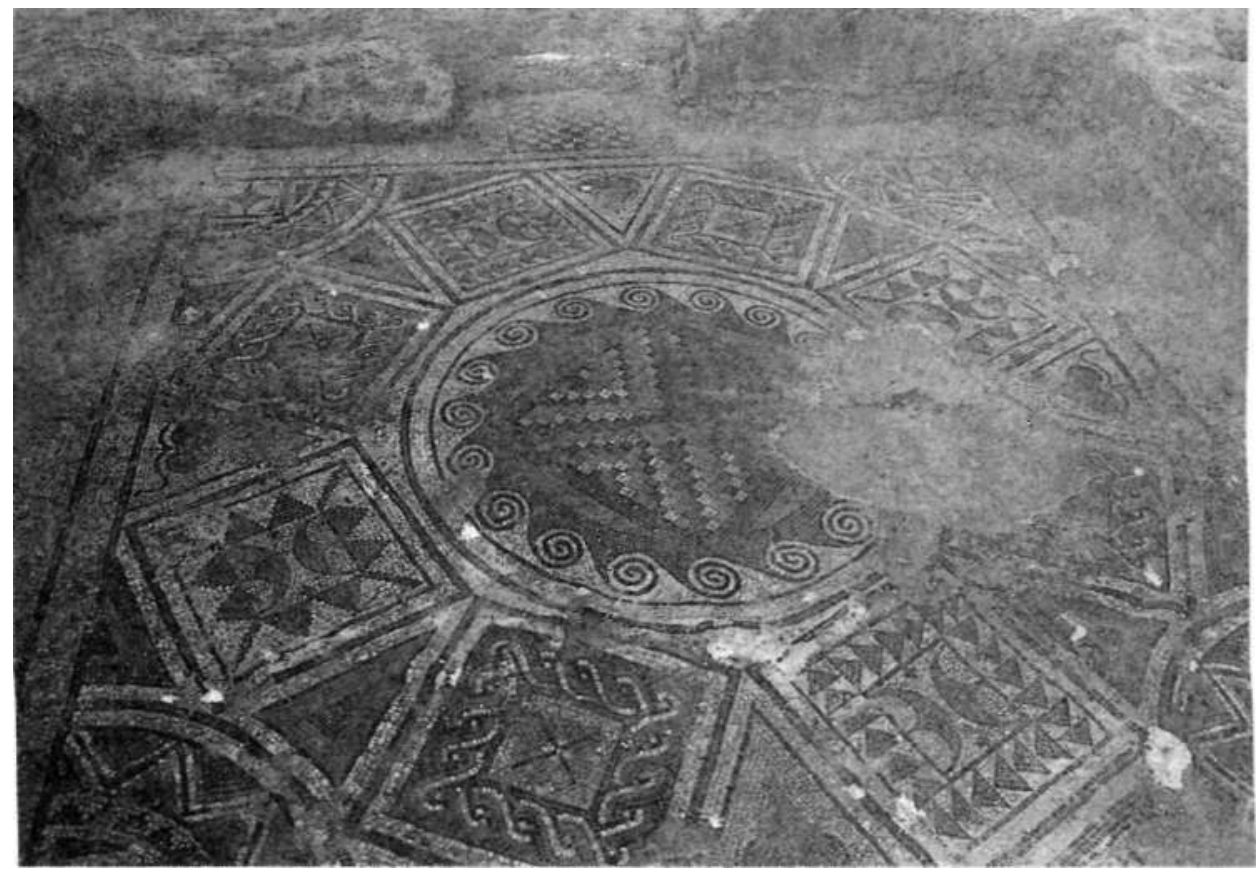

Lám. V. Mosaico con composición en nido de abeja.

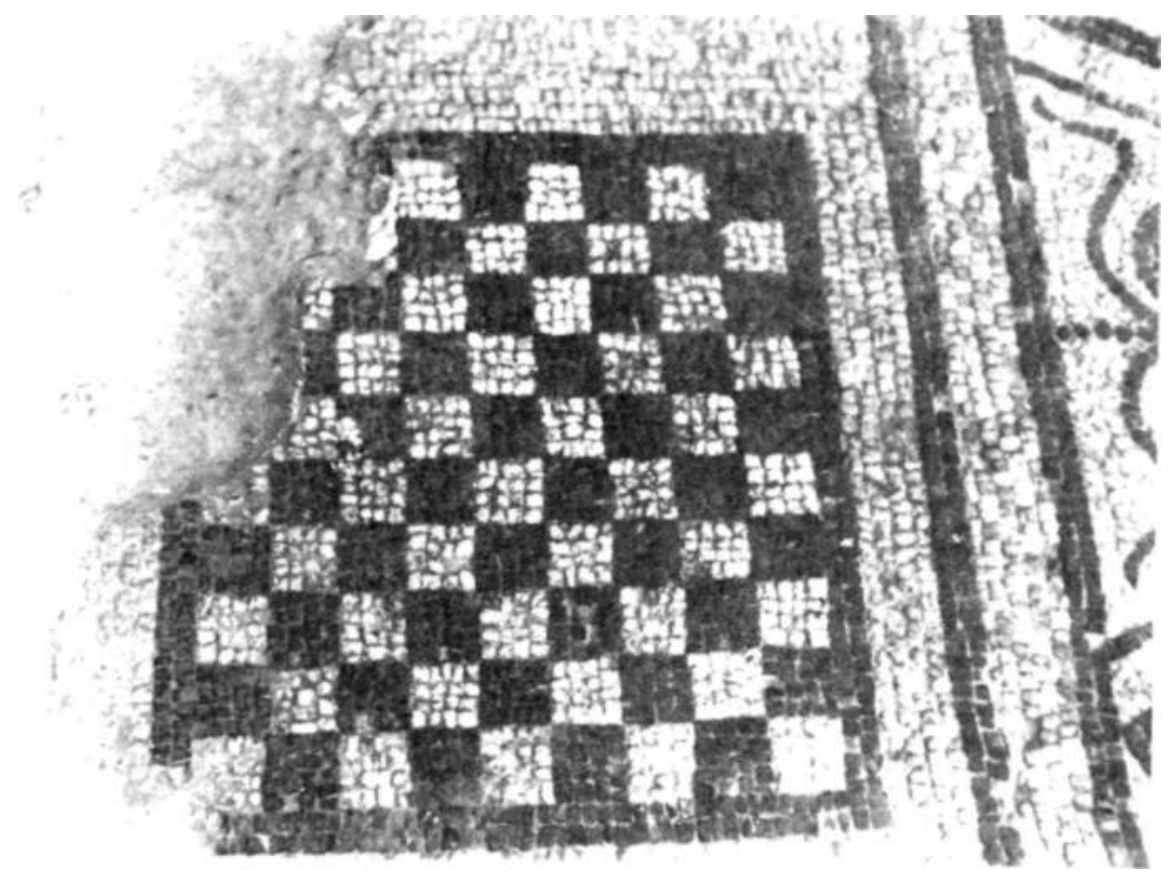

Lám. VI. Detalle del motivo de ajedrezado de la entrada. Mosaico 3. 


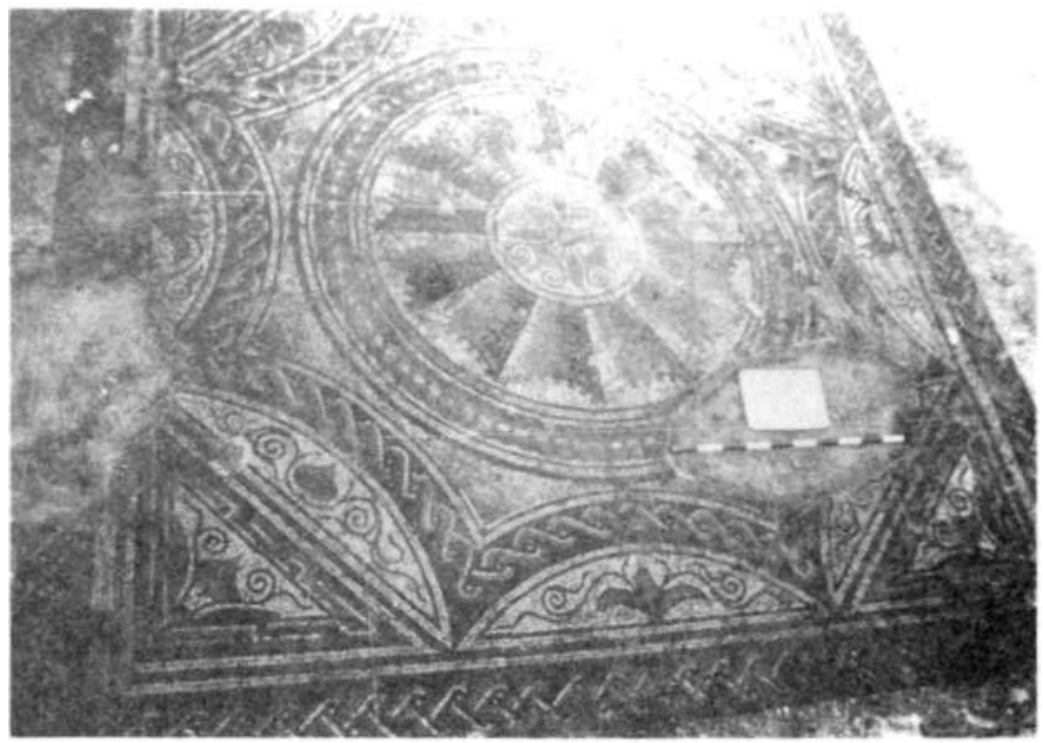

Lám. VIL Mosaico con aspas centrales (número 4).

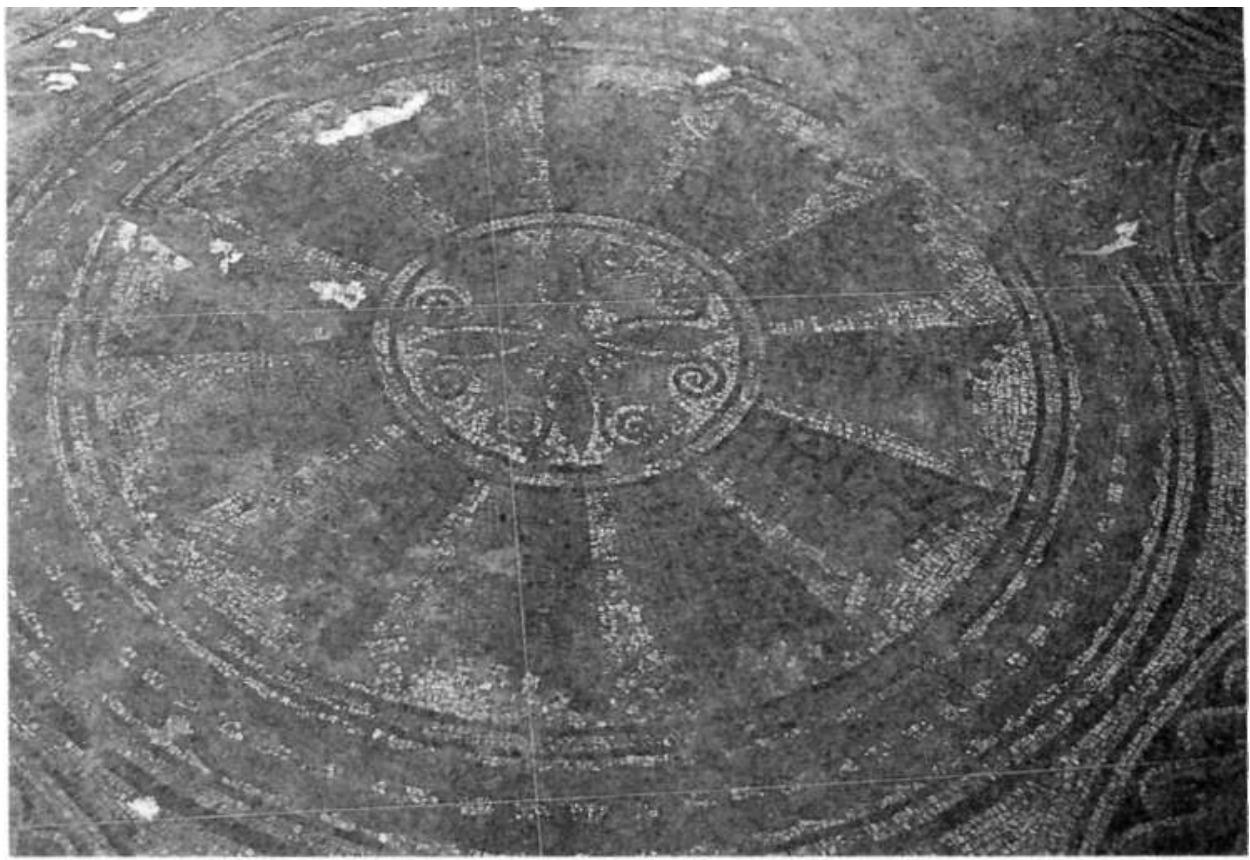

Lám. VIII. Detalle del motivo central del mosaico 4. 


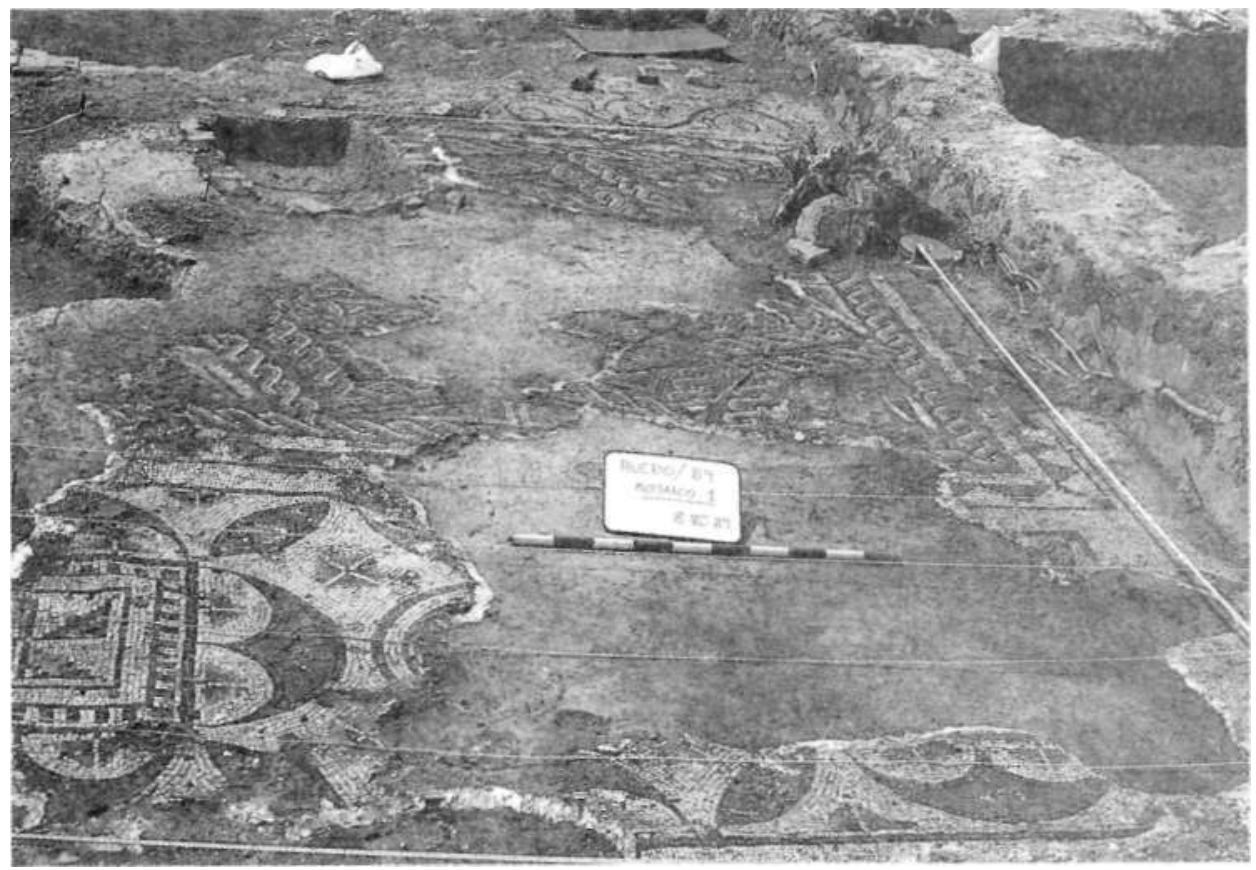

Lám. IX. Mosaico con cuadrados entrelazados y cuadrilóbulos de peltas.

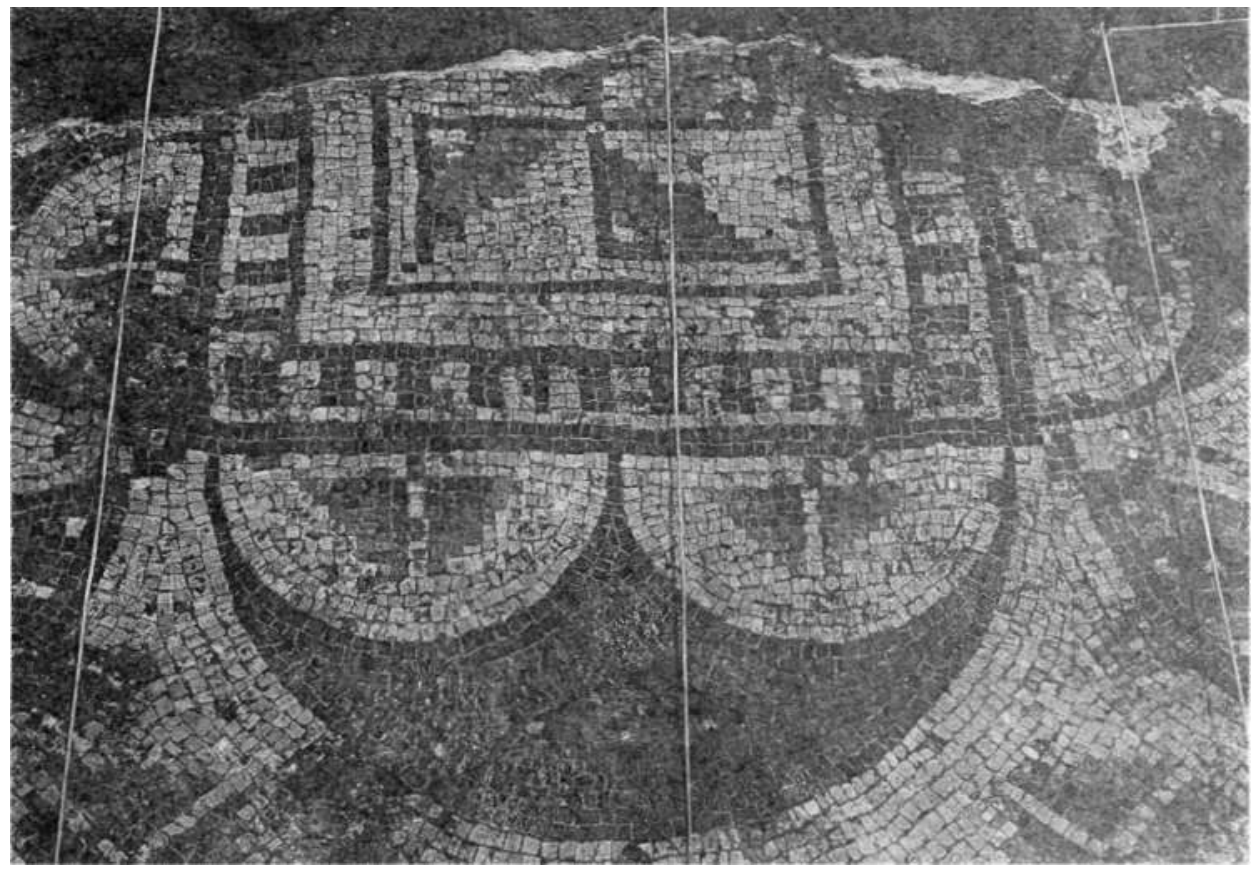

Lám. X. Detalle del cuadrilóbulo de peltas. Mosaico 5. 


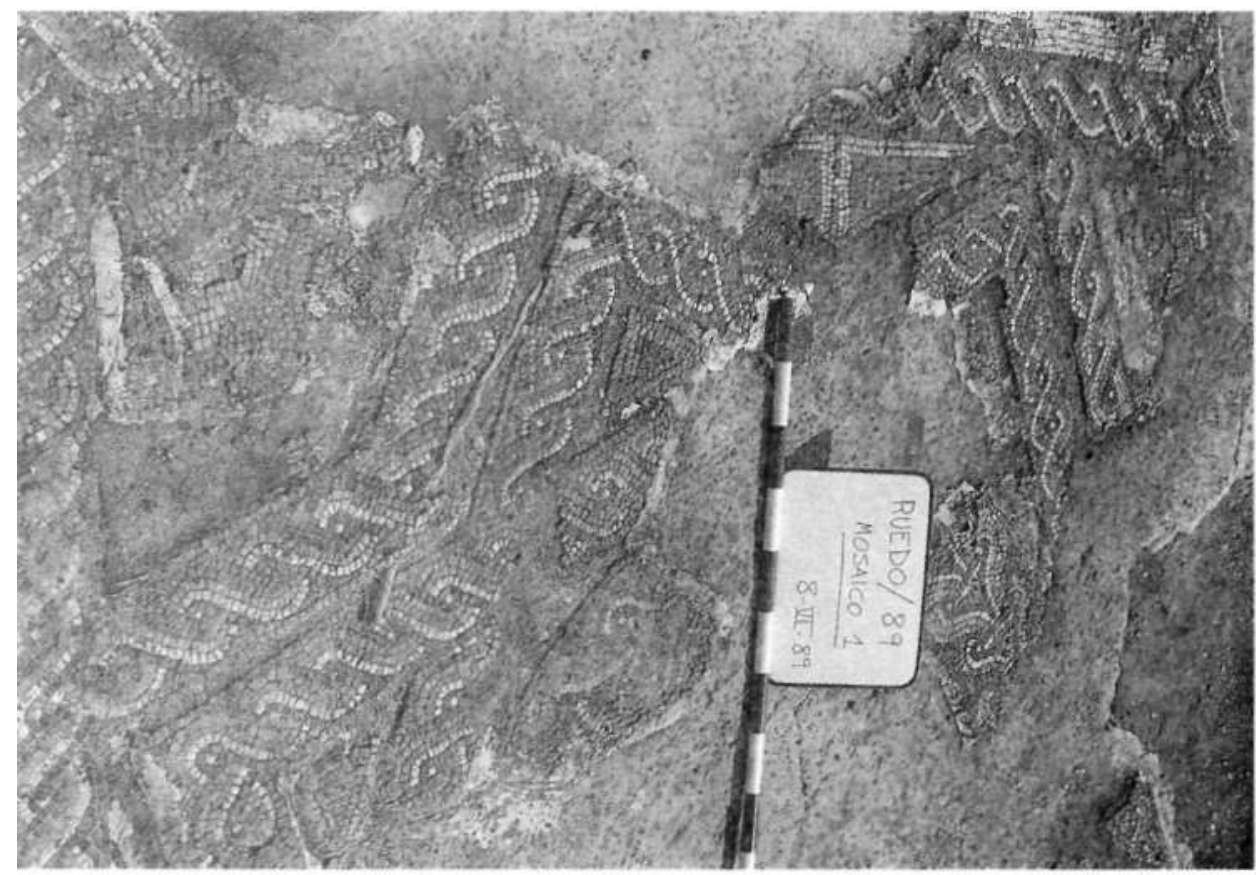

Lám. XI. Cuadrados entrelazados. Mosaico 5.

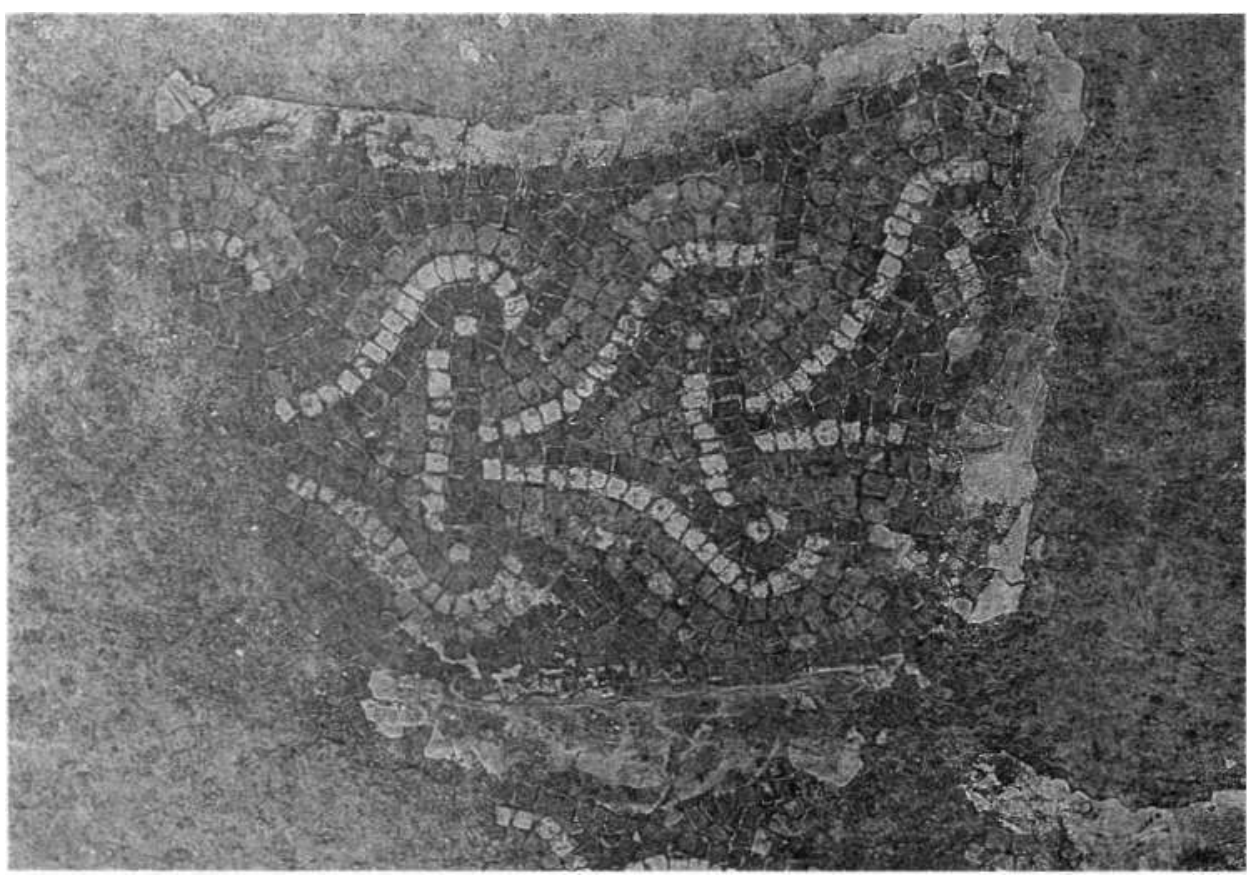

Lám. XII. Detalle del motivo de guiloches central. Mosaico 5. 


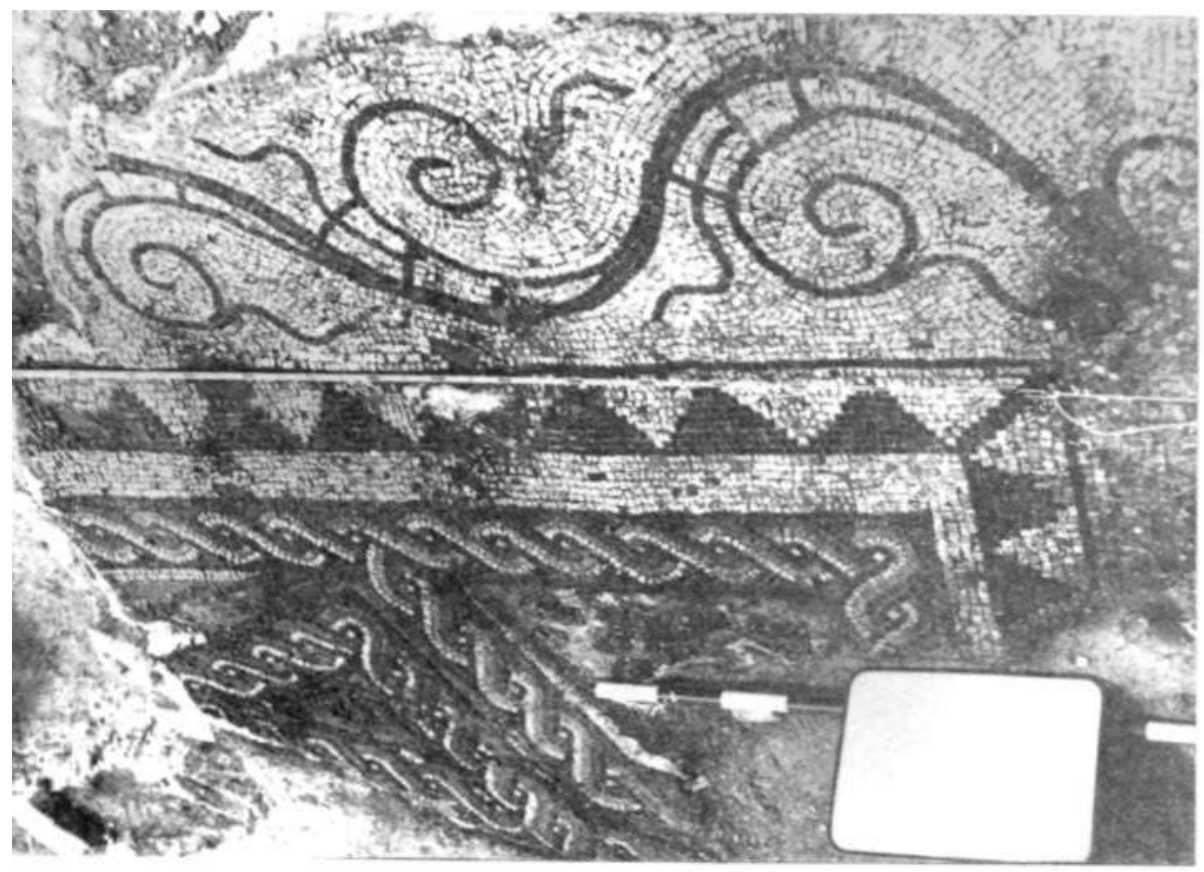

Lám. XIII. Orla de roleos del mosaico 5.

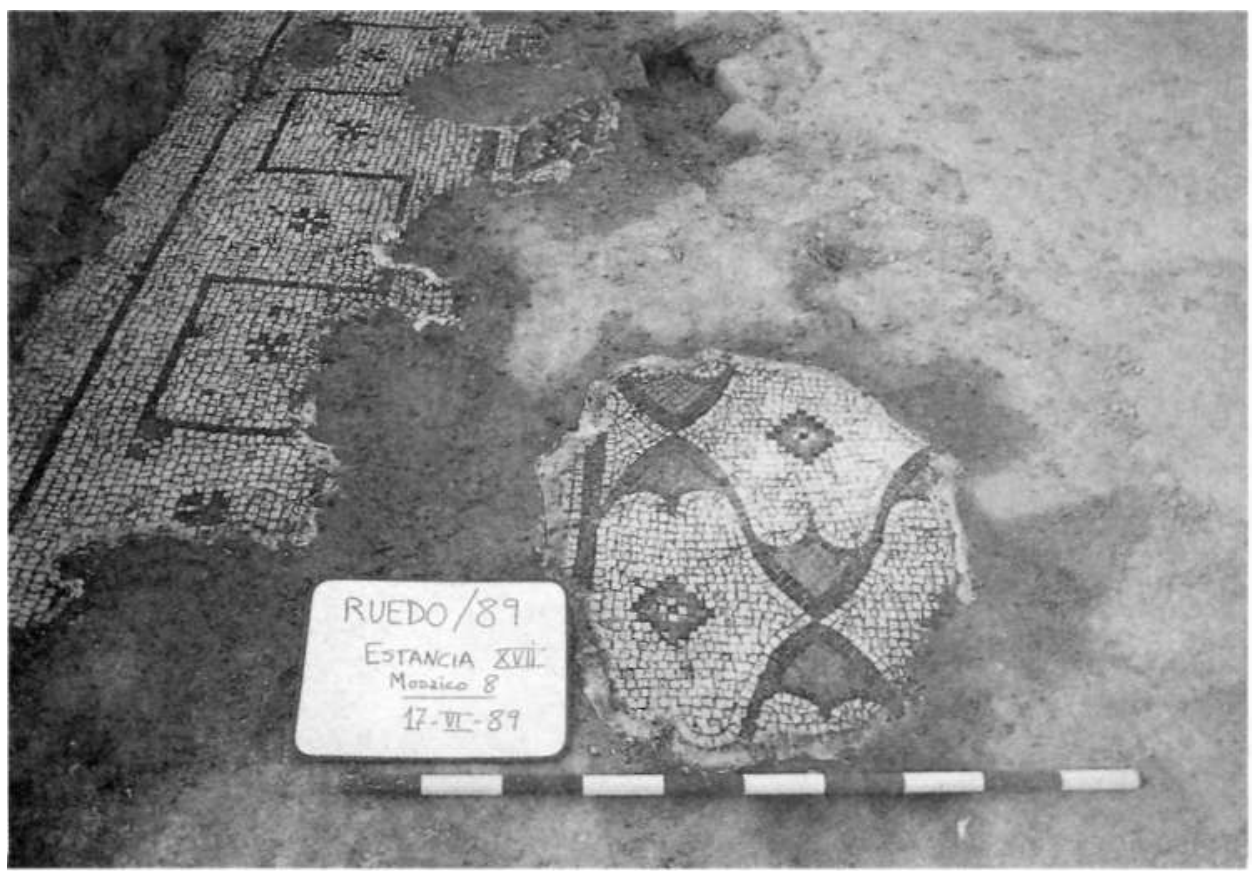

Lám. XIV. Mosaico con ondas de peltas. 


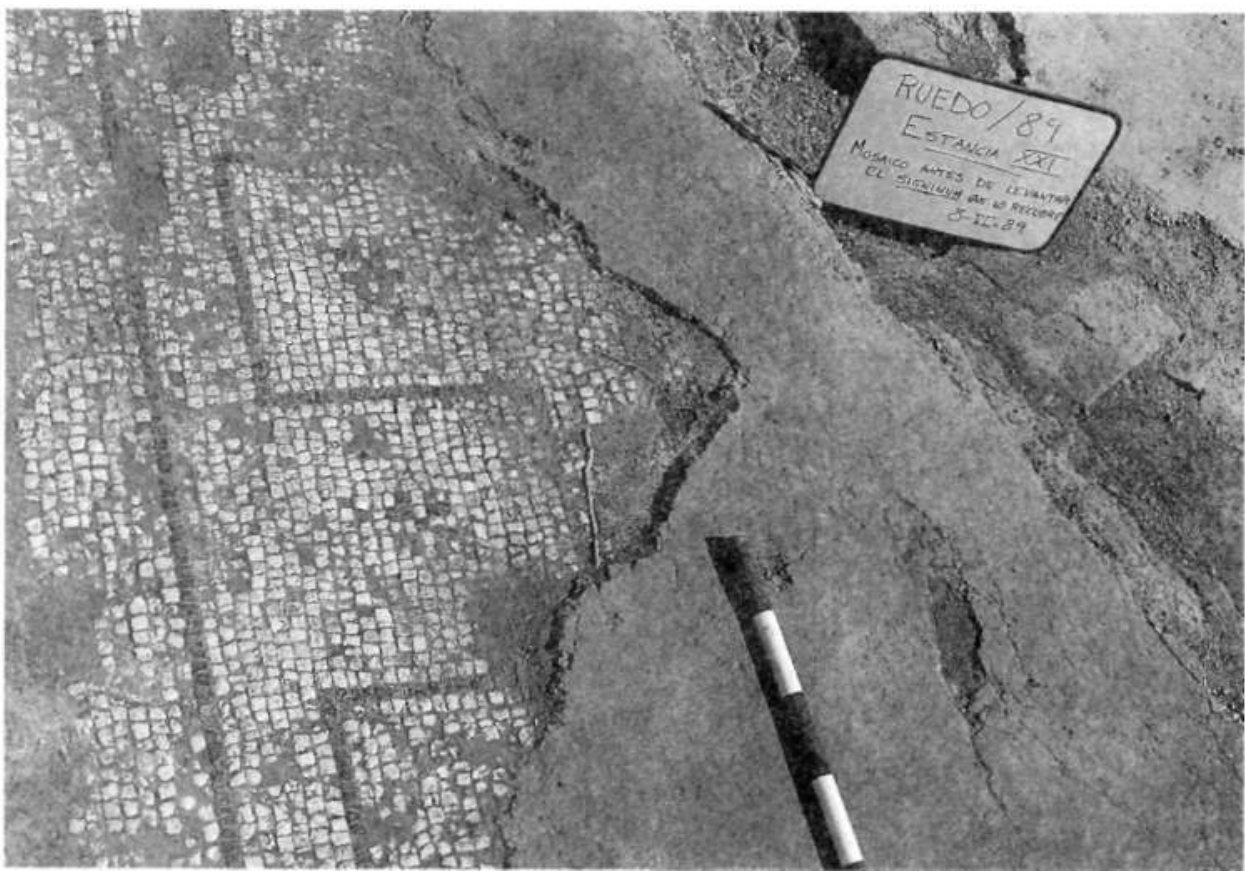

Lám. XV. Detalle del mosaico 7 y del pavimento que lo cubría.

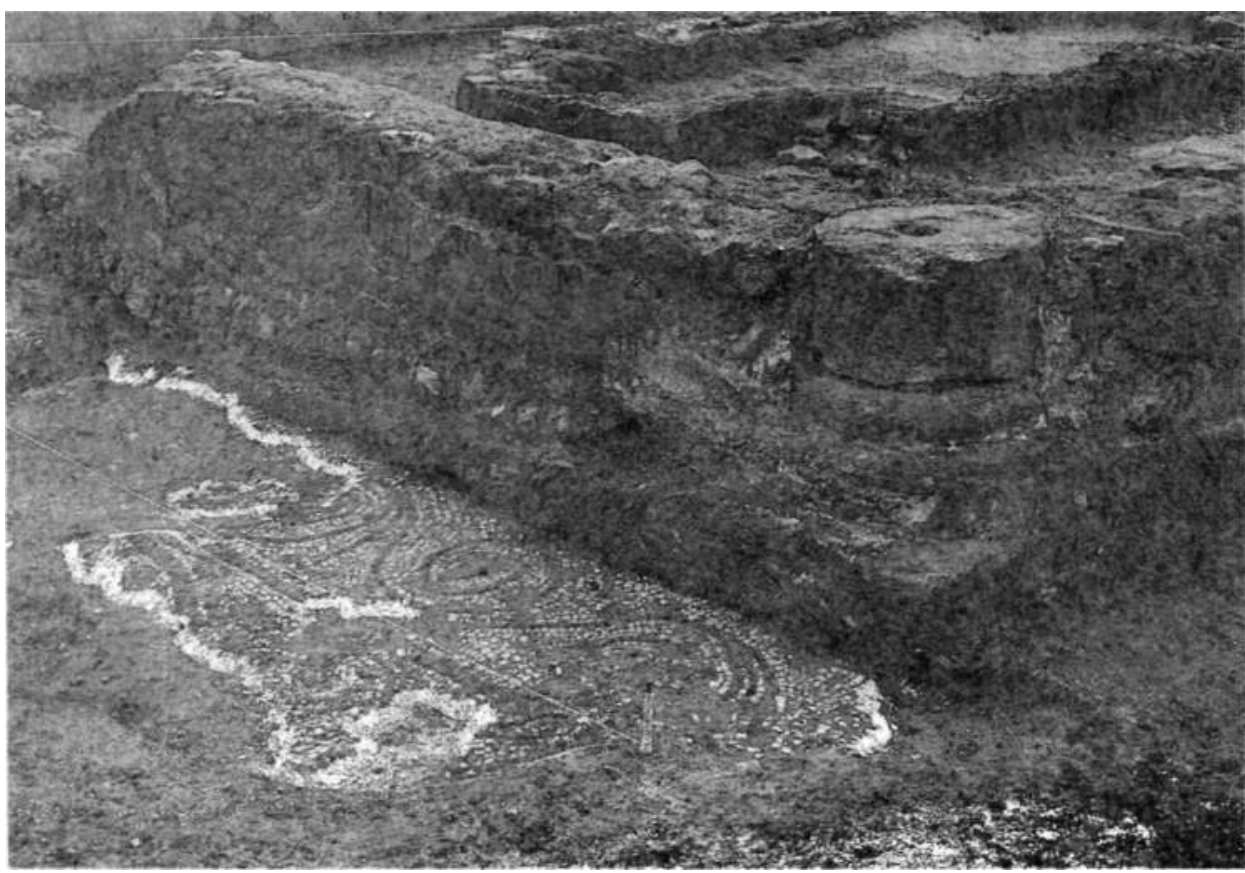

Lám. XVI. Ambulacrum norte. Mosaico 9. 


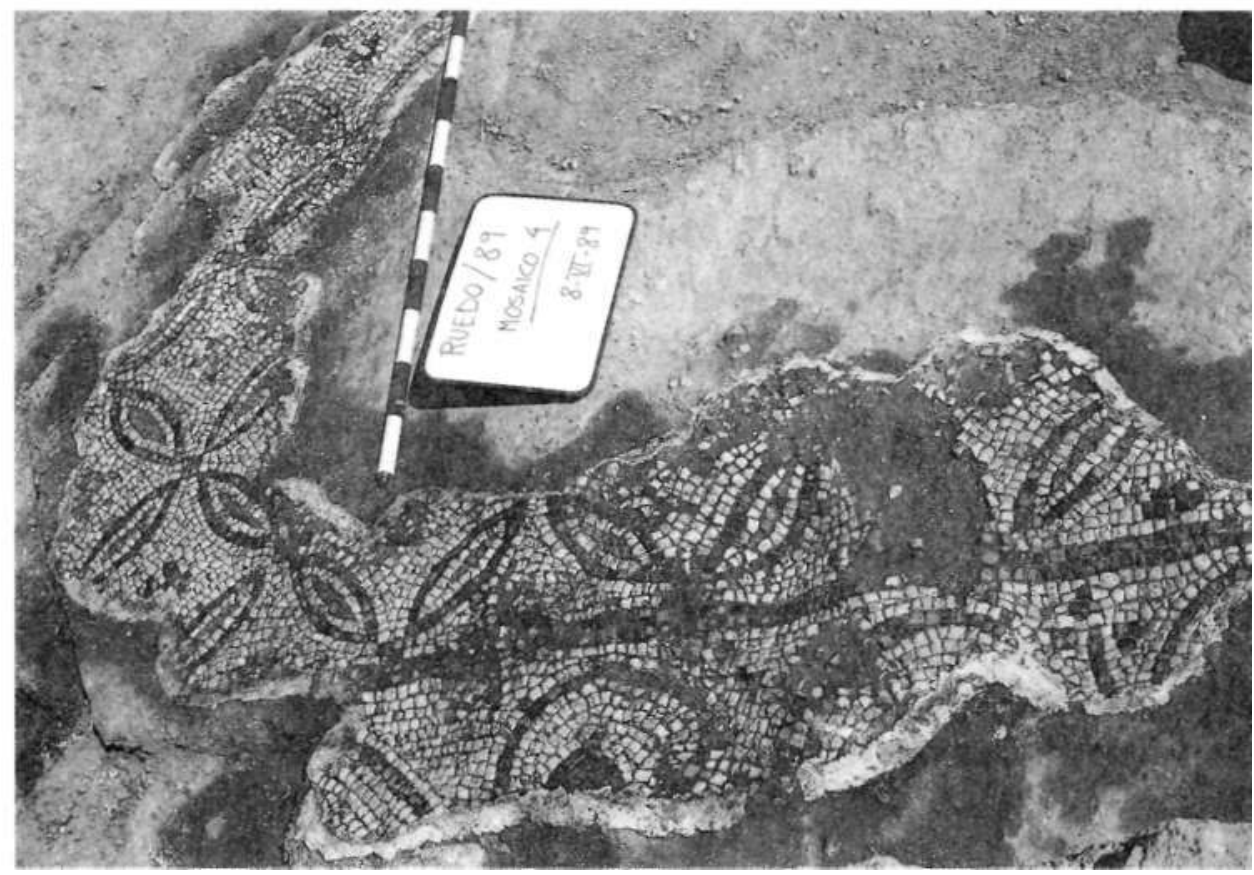

Lám. XVII. Mosaico de husos bícromos.

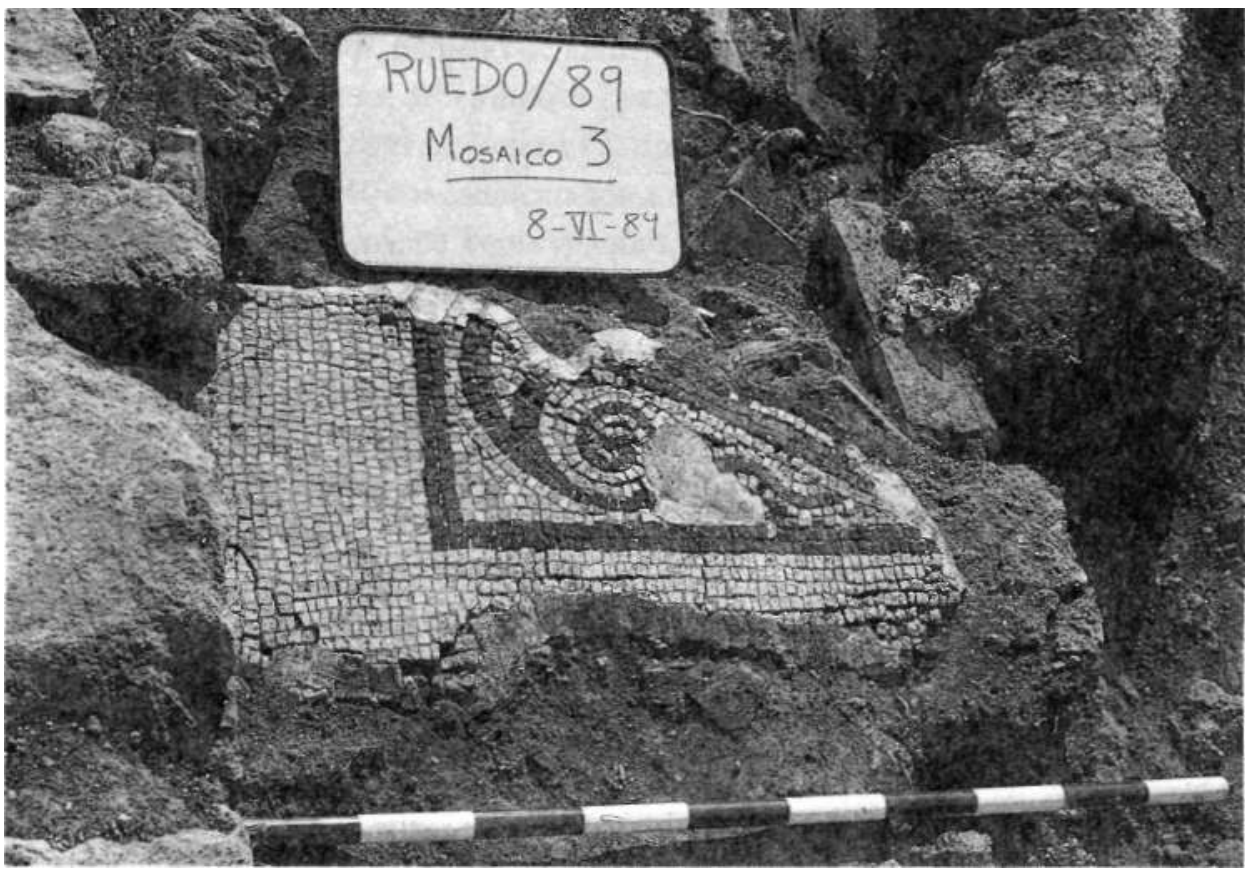

Lám. XVIII. Mosaico 10.3. 